\title{
TOWARDS OXY-STEAM COMBUSTION: THE EFFECT OF INCREASING THE STEAM CONCENTRATION ON COAL REACTIVITY
}

\author{
Cristina Dueso ${ }^{\mathrm{a}}$, M. Carmen Mayoral ${ }^{\mathrm{a}}$, J. Manuel Andrés $^{\mathrm{a}}$, Ana I. Escudero ${ }^{\mathrm{b}}$, Luis I. Díez ${ }^{\mathrm{b}}$ \\ ${ }^{a}$ Instituto de Carboquímica-CSIC, Miguel Luesma Castán 4, 50018 Zaragoza, Spain \\ ${ }^{\mathrm{b}}$ University of Zaragoza, Department of Mechanical Engineering, María de Luna s/n, 50018 \\ Zaragoza, Spain
}

\begin{abstract}
Oxy-steam combustion and devolatilization performance of three different coals (anthracite, blend of bituminous coals and low-rank coal) was studied in a thermobalance with a water vapour furnace under variable steam concentrations $\left(0,20,40\right.$ and 70 vol. $\left.\% \mathrm{H}_{2} \mathrm{O}\right)$ in $\mathrm{N}_{2}$ and $\mathrm{CO}_{2}$. Two oxygen concentrations were used during the combustion tests (20 and 30 vol.\%). Devolatilization behaviour was similar under $\mathrm{N}_{2}$ and $\mathrm{CO}_{2}$ atmosphere and increasing steam concentration did not affect significantly the observed reactivity and the reaction temperature range. Replacing $\mathrm{CO}_{2}$ with 20 vol. $\% \mathrm{H}_{2} \mathrm{O}$ during combustion tests produced a decrease in ignition and burnout temperatures. When $\mathrm{H}_{2} \mathrm{O}$ content increased to 40 and 70 vol.\%, this effect was only found with high-rank anthracite. Maximum mass loss rates for the low-rank coal with high volatile content were up to four times higher than with the other two coals. During direct oxidation experiments, DTG curves of anthracite and the coal blend showed a double peak corresponding to devolatilization and oxidation reactions. This allowed determining independent kinetic parameters $\left(E_{a}\right.$ and $\left.A\right)$ for both stages. An only DTG peak was detected with the low-rank coal since devolatilization and oxidation reactions took place simultaneously owing to its high reactivity. Devolatilization and oxidation kinetics followed a first-order reaction using the Coats-Redfern integral method. Significant differences were not observed between the activation energies of the three coals when comparing conventional $\left(\mathrm{N}_{2}\right)$, oxy-fuel $\left(\mathrm{CO}_{2}\right)$ and oxy-steam conditions $\left(70\right.$ vol.\% $\mathrm{H}_{2} \mathrm{O}$ in $\left.\mathrm{CO}_{2}\right)$, although $\mathrm{E}_{\mathrm{a}}$ values were higher for the devolatilization stage than for the oxidation process.
\end{abstract}




\section{Keywords}

Oxy-steam combustion, combustion kinetics, steam thermogravimetry, direct coal oxidation 


\section{Introduction}

Oxy-fuel combustion is one of the leading technologies for power generation from fossil fuels with $\mathrm{CO}_{2}$ capture, fast approaching the demonstration stage [1]. There is a great body of research encompassing combustion efficiency, heat transfer, pollutant formation and control, and ashes behaviour, in relation to the $\mathrm{O}_{2} / \mathrm{CO}_{2}$ atmosphere [2]. Important experience worldwide of coal oxy-combustion in pulverized fuel and fluidized bed units has been reached at different sizes $[3,4]$.

The main barrier for an extensive implementation of oxy-combustion technologies is the strong energy and economic penalties related to several processes, mainly oxygen production by means of cryogenic distillation, flue gas purification and compression stages. The so-called second generation oxy-combustion plants aim at diminishing those impacts by enhancing and optimizing the energy integration of the air separation unit and $\mathrm{CO}_{2}$ processing units within the water-steam cycle of the power plants [5].

A further step in efficiency is pursued researching the reduction and even suppression of recycled $\mathrm{CO}_{2}$ [6], as the "third generation" oxy-combustion processes. Among them, oxysteam combustion proposes the use of water vapour instead of recycled gases acting as temperature-moderation and fed mixed with the oxygen [7-9]. In this process, the exhaust gas contains mainly steam and $\mathrm{CO}_{2}$, which can be sent for compression and sequestration after the $\mathrm{H}_{2} \mathrm{O}$ condensation. Numerical studies of process simulation and thermodynamic assessment indicate that, with an accurate thermal integration, energy penalty due to steam formation from condensed water can be compensated with the avoidance of energy spent in gas recycling, flue gas separation, purification and compression [10-12]. The main advantages of this process, compared to $\mathrm{O}_{2} / \mathrm{CO}_{2}$ recycled combustion, are its major simplicity, diminution of operating cost, the reduction of the specific sizes of the furnaces and the inhibition of some pollutants formation [13], while permitting the use of current materials.

The influence of high partial pressure of $\mathrm{H}_{2} \mathrm{O}$ in flue gas on coal ignition, kinetics and char reactivity, flame stability and emissions has been deeply studied when considering a wetrecycle stream in oxy-fuel combustion. In thermogravimetric studies, it was found that replacing from 10 vol.\% to 40 vol.\% of $\mathrm{CO}_{2}$ by $\mathrm{H}_{2} \mathrm{O}$ strongly affected the combustion of coal and coal chars, shifting the oxy-combustion to lower temperatures and leading to faster burnout and higher reactivities $[14,15]$. It was proposed that the lower specific heat capacity of $\mathrm{H}_{2} \mathrm{O}$ and the enhanced $\mathrm{O}_{2}$ diffusivity in steam brought forward the combustion stage. On 
the other hand, the ignition point of coal particles were found to be higher from those in dry flue gas recycle combustion, both in numerical simulations and experimentally in entrained flow reactors and drop tubes $[16,17]$, indicating the influence of steam in the gasification and oxidation of the particle surface.

Higher steam concentration was used in non-isothermal thermogravimetric analysis to explore coal and char particle behaviour when gas conditions are those expected in oxy-steam combustion [18-20], with the final aim of obtaining kinetic parameters for process simulation. In the present work, a new approach to non-isothermal thermogravimetry is performed to a selection of coal samples to determine kinetic parameters of both devolatilization and oxidation in oxy-steam combustion under chemical reaction control regime. Direct oxidation of fuels in 70 vol.\% steam is used to obtain kinetic parameters, instead of using coal char for indirect determinations. Many studies available in literature about coal combustion $[15,19]$ address the combustion of coal char, previously prepared in a furnace under inert atmosphere. Nevertheless, when coal is used in a power station, this previous stage does not take place and coal is directly fed to the boiler. The combustion performance of the char and the coal could be distinct and, hence, in this work the direct oxidation of three coals under different oxygen concentrations in $\mathrm{N}_{2}$ and $\mathrm{CO}_{2}$ was investigated. The obtained information will be eventually used for a numerical modelling of oxy-steam systems [21].

\section{Experimental section}

\subsection{Coal samples}

The behaviour of three coals during devolatilization and combustion in the presence of high steam concentrations (up to $70 \mathrm{vol} . \%$ ) was investigated in this work. These coals were selected to illustrate the performance of coals with dissimilar compositions and characteristics, as shown in Table 1, which will significantly affect the devolatilization and oxidation processes. Coal A was anthracite from the North of Spain with a low content of volatiles and mainly composed of fixed carbon. Coal B was composed of a blend of different sub-bituminous coals with domestic high-sulphur lignite, as used in a Spanish thermal power station. In this case, volatiles increased to $26.4 \%$ while fixed carbon lessened in the same proportion. Indonesian coal, designated as coal $\mathrm{C}$ in this study, was distinguished by the low amount of ash (4.2\%) and higher content of volatiles (49.4\%). Before performing the experiments, coal samples were crushed and sieved to a particle size between 75 and $125 \mu \mathrm{m}$. 


\subsection{TGA study}

Coal devolatilization and combustion tests in oxy-steam atmosphere were performed in a Netzsch STA 449 thermogravimetric analyser under non-isothermal conditions. The thermobalance included a water vapour generator with a precision of $0.02 \mathrm{~g} / \mathrm{h}$. About $5 \mathrm{mg}$ of the coal were placed in an alumina crucible, heated up from $353 \mathrm{~K}$ to $423 \mathrm{~K}$ and held for 15 minutes in order to remove moisture. The drying period was not considered for further calculations. The size of the sample was selected to prevent any mass transfer limitations. After that, temperature was risen to $1173 \mathrm{~K}$ at $20 \mathrm{~K} / \mathrm{min}$ with a flow rate of $100 \mathrm{ml} / \mathrm{min}$ under different atmospheres.

Devolatilization behaviour was studied under variable steam concentrations: 0, 20, 40 and 70 vol.\%. Either nitrogen or $\mathrm{CO}_{2}$ were used as balance gas to study conventional combustion and oxy-fuel conditions, respectively. Combustion experiments were carried out in the presence of various steam concentrations $(0,20,40$ and 70 vol.\%) under two different oxygen concentrations (20 and 30 vol.\%) with $\mathrm{N}_{2}$ or $\mathrm{CO}_{2}$ to balance.

Different parameters calculated from the mass loss versus time and temperature data found in the TGA are generally accepted to describe the combustion behaviour of coal. The ignition temperature $\left(\mathrm{T}_{\mathrm{i}}\right)$ is the temperature at which coal combustion starts and was obtained according to the method described in [22]. The peak temperature $\left(\mathrm{T}_{\text {peak }}\right)$ corresponds to the temperature at which maximum rate of mass loss $\left(\mathrm{DTG}_{\mathrm{max}}\right)$ occurs. $\mathrm{T}_{\text {peak }}$ is inversely related to the reactivity of the coal while there is a direct proportional link between DTG $_{\max }$ and reactivity. The end of the coal oxidation is defined by the burnout temperature $\left(\mathrm{T}_{\mathrm{bo}}\right)$, taken as the temperature value at which the rate of mass loss was $1 \% / \mathrm{min}$ [19]. The more reactive a coal is the lower the value of $\mathrm{T}_{\mathrm{bo}}$ is observed. All these parameters were calculated for the combustion tests under different oxygen and steam concentrations in $\mathrm{N}_{2}$ and $\mathrm{CO}_{2}$.

\subsection{Kinetic model}

Devolatilization and combustion of coal are complex processes that involve many different reactions taking place simultaneously. When these processes are studied globally, independently of the reaction occurring at any moment, apparent kinetic parameters, i.e. activation energy and preexponential factor, can be obtained from the TG curves. Different authors $[15,18,23]$ have simulated the non-isothermal coal devolatilization or combustion using the Coats-Redfern integral method, generally described by the following equation: 
$\frac{\mathrm{d} \alpha}{\mathrm{dt}}=\mathrm{k}(\mathrm{T}) \cdot \mathrm{f}(\alpha)$

where $\alpha$ represents the conversion rate, calculated using Equation 2

$\alpha=\frac{\mathrm{w}_{0}-\mathrm{w}_{\mathrm{t}}}{\mathrm{w}_{0}-\mathrm{w}_{\mathrm{f}}}$

$\mathrm{w}_{0}$ and $\mathrm{w}_{\mathrm{f}}$ are the weight of the sample at the beginning and at the end of the reaction, respectively, while $\mathrm{w}_{\mathrm{t}}$ is the weight of the sample at time $\mathrm{t}$. The rate constant $\mathrm{k}$ follows an Arrhenius dependency with temperature according to the following expression:

$$
\mathrm{k}(\mathrm{T})=\mathrm{A} \cdot \mathrm{e}^{\left(-\frac{\mathrm{E}}{\mathrm{R} \cdot \mathrm{T}}\right)}
$$

When working under non-isothermal conditions, temperature varies with time. This variation of the heating rate, $\beta$, can be expressed as

$$
\beta=\frac{\mathrm{dT}}{\mathrm{dt}}
$$

Most authors have represented the devolatilization and combustion of coal by means of a first-order reaction $[15,24,25]$. Taking into account the previous equations, Equation 1 can be re-written as

$$
\frac{\mathrm{d} \alpha}{\mathrm{dt}}=\frac{\mathrm{A}}{\beta} \mathrm{e}^{\left(-\frac{\mathrm{E}}{\mathrm{R} \cdot \mathrm{T}}\right)} \cdot(1-\alpha)^{\mathrm{n}}
$$

Integrating Equation 5 and taking logarithms lead to the following expression

$$
\log \left[\frac{-\log (1-\alpha)}{T^{2}}\right]=\frac{-E}{R \cdot T}+\log \left(\frac{A \cdot R}{\beta \cdot E}\right)
$$

The plot of $\log \left[\frac{-\log (1-\alpha)}{\mathrm{T}^{2}}\right]$ versus $1 / \mathrm{T}$ obtained from the thermogravimetric data should be a straight line. The activation energy, $\mathrm{E}_{\mathrm{a}}$, can be determined by the slope of the line while the preexponential factor, A, can be calculated from the value of the ordinate at the origin. 


\section{Results and discussion}

\subsection{Devolatilization of coal under $\mathrm{H}_{2} \mathrm{O} / \mathrm{N}_{2}$ and $\mathrm{H}_{2} \mathrm{O} / \mathrm{CO}_{2}$ atmospheres}

Devolatilization is the first stage in the combustion process, followed by the combustion of the resulting solid residue, i.e. char. A deep knowledge of the devolatilization process helps to understand the performance of coal during combustion. The TG curves obtained during devolatilization tests with increasing steam concentrations in $\mathrm{N}_{2}$ and $\mathrm{CO}_{2}$ are depicted in Figure 1 . When coal A was heated up to $1173 \mathrm{~K}$ in the presence of pure $\mathrm{N}_{2}$, only $4.8 \mathrm{wt} . \%$ of the dried sample weight was lost as evolved volatiles, indicating the low reactivity and stable structure of anthracite (coal A) [26] as a high-rank coal, compared with the higher volatilecontent coals, B and C. When $\mathrm{N}_{2}$ was replaced by $\mathrm{CO}_{2}$ under oxy-fuel conditions, the initial section of the curve, corresponding to the main devolatilization process, was almost overlapped for the three coals. Hence, TGA data suggested that substitution of $\mathrm{N}_{2}$ by $\mathrm{CO}_{2}$ had a limited effect on the devolatilization for all coals studied. Further gasification took place with $\mathrm{CO}_{2}$ as expected, which contributed to the additional weight loss in the highest temperature zone, $2.6 \%$ for coal A, $17.5 \%$ for coal B and $40.6 \%$ for coal C.

Experiments with several steam concentrations in $\mathrm{N}_{2}$ were carried out with the three coals, $\mathrm{A}$, B and C. Gasification reaction with the steam happened and a further weight loss was observed at the end of the reaction period in the same way as with $\mathrm{CO}_{2}$. Weight loss decrease was significantly larger when 20 vol.\% of steam replaced part of the nitrogen, e.g. $50.8 \%$ in pure $\mathrm{N}_{2}$ and $93.4 \%$ in $20 \% \mathrm{H}_{2} \mathrm{O} / 80 \% \mathrm{~N}_{2}$ for coal C. When steam concentration increased up to 40 and $70 \mathrm{vol} \%$, the sample weight was further reduced but in a lower extension, with similar values under both steam concentrations. Addition of steam to $\mathrm{CO}_{2}$ in different proportions also increased the weight loss observed with respect to that obtained with pure $\mathrm{CO}_{2}$. However, equal concentrations of steam in either $\mathrm{N}_{2}$ or $\mathrm{CO}_{2}$ led to similar final weight loss with differences lower than $2 \%$. Xu et al. [20] attributed these results to the competition for the active sites during the char reactions with $\mathrm{H}_{2} \mathrm{O}$ and $\mathrm{CO}_{2}$, since these reactions take place simultaneously. Chen at al. [27] found that char gasification rate in mixtures of $\mathrm{CO}_{2}$ and $\mathrm{H}_{2} \mathrm{O}$ was lower than the sum of the two rates but higher than the rate of each independent reaction.

DTG curves in $\% /$ min are shown in Figure 2 and allow the study of the devolatilization stage below $1000 \mathrm{~K}$. As the volatile content of anthracite (coal A) was very low, the first peak observed between 680 and $900 \mathrm{~K}$ was almost negligible. Devolatilization reaction rates were 
in the range $-0.3--0.5 \% / \mathrm{min}$ supporting the low reactivity of this kind of coal. Indonesian coal (coal C) was the most reactive and the devolatilization peak was detected at lower temperatures $(679-691 \mathrm{~K})$ than with coal A (815-879K). Maximum reaction rates for devolatilization were in the interval -5.4 to $-5.9 \% / \mathrm{min}$, whereas coal B reacted at lower rates, between -2.2 and $-2.5 \% / \mathrm{min}$, and at intermediate temperatures (700-722 K). The DTG curves obtained during devolatilization of coal B with steam contents between 20 and 70 vol.\% showed an additional peak at temperatures between 770 and $930 \mathrm{~K}$. This could be explained considering the characteristics of the coal, composed of a blend of coals with different properties. According to $\mathrm{Mu}$ et al. [28], some of the components of the blend could decompose at higher temperatures due to the presence of stronger chemical bonds and, as a consequence, at lower rates.

As can be seen in Figure 2, the presence of steam did not involve significant changes in peak DTG temperatures. Peak temperatures were also very similar when devolatilization was performed in both $\mathrm{N}_{2}$ and $\mathrm{CO}_{2}$ working with all the studied coals. In addition, increasing steam concentrations up to $70 \mathrm{vol} \%$ only produced slight increments in the reaction rate. A deeper evaluation of the steam influence on the reaction rate will be performed from the calculation of the kinetic parameters in the following section.

\subsubsection{Devolatilization kinetics}

Kinetic parameters for the devolatilization process of coals B and C under variable steam concentrations in $\mathrm{N}_{2}$ and $\mathrm{CO}_{2}$ were determined using the model explained in section 2.3 of this work. Activation energy $\left(E_{a}\right)$ was estimated from the slope of the plot $\log \left[\frac{-\log (1-\alpha)}{T^{2}}\right]$ vs. $1 / \mathrm{T}$, while preexponential factor, $\mathrm{A}$, was calculated from the ordinate at the origin of this straight line. Previous analysis demonstrated that it was not possible to represent the entire range of data with a single straight line. Experimental data had to be divided in two different zones, corresponding to devolatilization and gasification reactions, where kinetic parameters could be determined separately. TG data from $\alpha=0.05$ to $750 \mathrm{~K}$ were considered for the devolatilization kinetics determination. This temperature corresponded to upper $\alpha$ values in the range $0.26-0.31$ and $0.3-0.32$ for coal $\mathrm{B}$ and coal $\mathrm{C}$, respectively, ensuring that only pyrolysis took place and gasification part was avoided. Second decomposition peak in coal B was also avoided. Devolatilization kinetics of coal A was not calculated in this work. 
Table 2 shows the calculated values of activation energy and preexponential factor for the devolatilization of coal B and coal C. As all $\mathrm{R}^{2}$ values were higher than 0.955 , the adjustment between the proposed model and the experimental data was considered reliable. Preexponential factor and activation energy were directly related through the following expressions:

\section{Coal B}

$\mathrm{CO}_{2}: \ln \mathrm{A}=0.188 \cdot \mathrm{E}_{\mathrm{a}}-4.041$

$$
\mathrm{R}^{2}=0.998
$$

$\mathrm{N}_{2}: \ln \mathrm{A}=0.239 \cdot \mathrm{E}_{\mathrm{a}}-5.518$

$$
\mathrm{R}^{2}=0.999
$$

Coal C

$\mathrm{CO}_{2}: \ln \mathrm{A}=0.221 \cdot \mathrm{E}_{\mathrm{a}}-5.080$

$$
\mathrm{R}^{2}=0.999
$$

$\mathrm{N}_{2}: \ln \mathrm{A}=0.265 \cdot \mathrm{E}_{\mathrm{a}}-6.689$

This linear relationship between $\mathrm{E}_{\mathrm{a}}$ and $\mathrm{A}$ is known as the kinetic compensation effect [24]. If $\mathrm{R}^{2}$ value is close to 1 , this indicates that the selected reaction order is appropriate to describe the experimental data [29].

Activation energy is defined as the minimum energy necessary to break the chemical bonds of the involved species and start the reaction. Therefore, a low activation energy means that the reaction is facilitated and the reaction rate should be higher [28]. Activation energy values were very low for both coals in all studied conditions. When coal B was utilized, $\mathrm{E}_{\mathrm{a}}$ was in the range 26.7-41.3 kJ/mol, while $\mathrm{E}_{\mathrm{a}}$ varied between 38.0 and $47.5 \mathrm{~kJ} / \mathrm{mol}$ for coal $\mathrm{C}$. Typical $\mathrm{E}_{\mathrm{a}}$ values obtained by other authors in $\mathrm{N}_{2}$ atmosphere with different coals varied from 150 $\mathrm{kJ} / \mathrm{mol}$ [29] to $282 \mathrm{~kJ} / \mathrm{mol}$ [28] at $\alpha=0.3$, while in $\mathrm{CO}_{2}$ a value of $120 \mathrm{~kJ} / \mathrm{mol}$ was found [29]. Güneş et al. [25] used the same kinetic model to evaluate the devolatilization kinetics of 12 Turkish coals with different characteristics. For some of them, in order to get a good adjustment, experimental data had to be divided into two or even three different zones where kinetic parameters were determined independently. $E_{a}$ values were also very low in comparison with literature data, from 3.85 to $61.56 \mathrm{~kJ} / \mathrm{mol}$, and this was attributed to the representation of the large number of reactions taken place during devolatilization by a single first order reaction.

For both coals, $\mathrm{E}_{\mathrm{a}}$ was higher in $\mathrm{N}_{2}$ devolatilization than in $\mathrm{CO}_{2}$ devolatilization without water. Addition of steam decreased $\mathrm{E}_{\mathrm{a}}$ when $\mathrm{N}_{2}$ was the balance gas for both coals, and increased when added to $\mathrm{CO}_{2}$. $\mathrm{E}_{\mathrm{a}}$ values with 40 and 70 vol.\% of $\mathrm{H}_{2} \mathrm{O}$ were roughly the same. 
These results indicate that the activation energy of coal devolatilization is dependent on the gas environment following this trend: $\mathrm{E}_{\mathrm{a}}$ in $\mathrm{N}_{2}>\mathrm{E}_{\mathrm{a}}$ in oxy-steam $\left(70 \% \mathrm{H}_{2} \mathrm{O} / 30 \% \mathrm{CO}_{2}\right)>\mathrm{E}_{\mathrm{a}}$ in $\mathrm{CO}_{2}$, for both coals studied.

\subsection{Combustion of coal in $\mathrm{O}_{2} / \mathrm{N}_{2}$ and $\mathrm{O}_{2} / \mathrm{CO}_{2}$ atmospheres}

The TG and DTG curves obtained with coal A, B and C under 20 vol.\% and 30 vol.\% of oxygen in conventional combustion $\left(\mathrm{N}_{2}\right)$ and oxy-fuel $\left(\mathrm{CO}_{2}\right)$ atmospheres are depicted in Figures 3 and 4, respectively. Significant differences can be observed in both kinds of curves depending of the characteristics of the coal and the reaction atmosphere. The higher reactivity of coal C (Indonesian) was illustrated by lower reactions temperatures and a higher slope in the TG curve, while coal A (anthracite) started to be burnt at temperatures about $200 \mathrm{~K}$ higher. Coal B presented an intermediate reactivity and a clear slope change at about $750 \mathrm{~K}$, indicating the presence of two different stages during the oxidation reaction. The same effect was found with coal A.

In the DTG curves from Figure 4, two peaks were detected for the experiments with coal A and coal B. The first one at lower temperatures could be assigned to the devolatilization process while the latter corresponded to the combustion of the solid char formed in the previous step. Some authors $[22,30]$ also observed two peaks during direct oxidation of coal. Niu et al. [23] explained the presence of two DTG peaks during the combustion of anthracite in $20 \% \mathrm{O}_{2}-80 \% \mathrm{CO}_{2}$ by the deeper coalification of this coal, with high fixed-carbon amount and low volatile matter content. The volatile fraction was released at lower temperatures. When temperature rose, the growing heat transfer facilitated the ignition and subsequent oxidation. Nevertheless, other works in literature $[14,18,31]$ about coal oxidation show an only peak even working with coals with similar properties and composition as coal A and coal B. Coal C presented an only noticeable peak with $\mathrm{DTG}_{\max }$ up to four times higher than with the other two coals tested and without an obvious separation between the devolatilization and oxidation steps, that took place simultaneously duo to its high reactivity.

When $\mathrm{N}_{2}$ was replaced by $\mathrm{CO}_{2}$, the TG curves were shifted to higher temperatures for the three coals at the same oxygen concentration. Combustion process was delayed in oxy-fuel conditions with respect to conventional combustion in $\mathrm{N}_{2}$ and this effect was more pronounced than in the devolatilization experiments. Significant differences were also observed in the maximum reactivity, DTG $_{\max }$, especially with coal C. Consequently, oxy-fuel 
conditions are less propitious for coal combustion than conventional combustion in air. This agrees with the data published in literature [29, 32], where these dissimilarities between the combustion behaviours were attributed to differences in the $\mathrm{N}_{2}$ and $\mathrm{CO}_{2}$ properties [14]. Figure 5a shows the evolution of the specific heat of $\mathrm{CO}_{2}$ and $\mathrm{N}_{2}$ with temperature calculated with the thermodynamic software HSC Chemistry. Due to the higher specific heat of $\mathrm{CO}_{2}$ with respect to the $\mathrm{N}_{2}$ one, this gas might act as a heat sink, reducing coal particle temperatures so that higher temperatures were needed to attain combustion.

The effect of the oxygen concentration was also investigated. The TG and DTG curves obtained during the experiments carried out with 20 and 30 vol.\% of oxygen in combustion and oxy-fuel atmospheres are represented in Figures 3 and 4. An increasing content of oxygen improved the combustion performance in all tests. TG and DTG curves were shifted to lower temperatures. Riaza et al. [16] observed a decrease in the ignition temperature when the oxygen concentration increased during the oxidation of two Spanish coals. They attributed these results to the higher oxygen flux of oxygen to the coal surface particles. Therefore, the rate of devolatilization and oxidation increases and the auto-ignition time is shortened. Figure $5 \mathrm{~b}$ displays the values of the diffusion coefficient of $\mathrm{O}_{2}$ in $\mathrm{CO}_{2}, \mathrm{~N}_{2}$ and $\mathrm{H}_{2} \mathrm{O}$. Oxygen transport in gas phase to the particle surface is hindered by the lower diffusion coefficient in $\mathrm{CO}_{2}$, which might play a role in decreasing combustion rates $[32,33]$.

Figure 6 explains how the characteristic temperatures where determined in this research. In the case of coal A and coal B, where two different peaks were found in the DTG curves, DTG $_{\max }$ corresponded to the maximum rate of the second peak, i.e. the oxidation peak. Therefore, $T_{\text {peak }}$ was the temperature at which $D G_{\max }$ occurred. $T_{i}$ was estimated using the method described in [22] from the second DTG peak as illustrated in Figure 6.

Figure 7 shows the characteristic combustion temperatures and the maximum combustion rate for the experiments with coals $\mathrm{A}, \mathrm{B}$ and $\mathrm{C}$ without steam and under 20 and 30 vol.\% $\mathrm{O}_{2}$. Different reactivities of the three coals affected the values of the characteristic temperatures. An augmentation of the reactivity from coal $\mathrm{A}$ to coal $\mathrm{C}$ caused the lessening of the characteristic temperatures at the same time that the maximum oxidation rate increased. The effect of the variation of oxygen concentration is clearly displayed in Figure 7 where characteristics temperatures $\left(\mathrm{T}_{\mathrm{i}}, \mathrm{T}_{\text {peak }}\right.$ and $\left.\mathrm{T}_{\mathrm{bo}}\right)$ decreased with an increasing oxygen concentration in all conditions and with all coals studied. The most important effect was found for the reaction rate with coal C, where $\mathrm{DTG}_{\max }$ decreased in great extent under both $\mathrm{N}_{2}$ and $\mathrm{CO}_{2}$ when oxygen concentration varied from 20 to 30 vol. $\%$. 


\subsection{Combustion of coal in $\mathrm{H}_{2} \mathrm{O} / \mathrm{O}_{2} / \mathrm{N}_{2}$ and $\mathrm{H}_{2} \mathrm{O} / \mathrm{O}_{2} / \mathrm{CO}_{2}$ atmospheres}

The combustion of coal in oxy-steam conditions with high steam concentrations was studied in this work. The TG combustion profiles obtained in 20 and 30 vol.\% of oxygen with variable steam concentrations when $\mathrm{CO}_{2}$ and $\mathrm{N}_{2}$ were used are shown in Figure 8. When coal A and $\mathrm{C}$ were tested in $\mathrm{N}_{2}$ atmosphere, only experiments without steam were performed with comparison purposes. DTG curves are represented in Figure 9.

Only slight differences were detected in the TG combustion profiles between experiments with variable steam concentrations in Figure 8. TG graphs were almost overlapped mainly with coal B in all the studied operating conditions. Nevertheless, an effect of the addition of steam in coal A and coal C was noted in Figure 9. An increase in steam concentrations shifted the DTG curves to a lower temperature zone, suggesting a diminution of the characteristic combustion temperatures. These dissimilarities were especially noticeable in the DTG profiles for coal C in oxy-fuel conditions (Figure 9) where the addition of steam caused a clear increase in the mass loss rate.

As TG and DTG profiles did not allow inferring clearly how high concentrations of steam affected the combustion process, comparison between different operating conditions was made taking into account the characteristic temperatures of the oxidation peak, calculated as explained in section 3.2. Figure 10 shows the characteristic combustion temperatures and the maximum combustion rate for the experiments with coals $\mathrm{A}, \mathrm{B}$ and $\mathrm{C}$ as a function of $\mathrm{H}_{2} \mathrm{O}$ concentration. Coal reactivity, directly related to coal rank as explained above, affected the values of the characteristic temperatures. There was a diminution of temperatures from the high-rank coal A to the most reactive coal C. Significant differences were observed in terms of the maximum mass loss rate, with 4 times higher values for coal $\mathrm{C}$ than for coals $\mathrm{A}$ and $\mathrm{B}$.

For all coals studied, addition of 20 vol. $\% \mathrm{H}_{2} \mathrm{O}$ replacing $\mathrm{CO}_{2}$ produced a reduction in characteristic temperatures under 20 and 30 vol.\% $\mathrm{O}_{2}$. However, when coal B performance was studied in $\mathrm{N}_{2}$ atmosphere, addition of 20 vol.\% of steam caused the opposite effect with a significant reduction in the characteristic temperatures with 20 vol. $\% \mathrm{O}_{2}$ and similar temperatures in 30 vol.\%. Previous studies confirmed the reduction of the characteristic temperatures under oxy-steam atmosphere $[13,19,34,35]$ in the same way as this work presents. Gil et al. [14] analysed the combustion behaviour of coal/biomass blends in a TGA and observed that DTG curves were shifted to lower temperatures with 10 and 20 vol.\% of steam probably owing to the lower specific heat capacity of $\mathrm{H}_{2} \mathrm{O}$. This increases the gas 
temperatures and, in consequence, the coal particle temperature what leads to lower $T_{i}$ and $\mathrm{T}_{\text {bo }}$. Heat capacities of the $\mathrm{O}_{2} / \mathrm{H}_{2} \mathrm{O} / \mathrm{N}_{2}$ and $\mathrm{O}_{2} / \mathrm{H}_{2} \mathrm{O} / \mathrm{CO}_{2}$ mixtures used in this research were determined from individual $C_{p}$ values in Figure 5a and are summarized in Figures 11a and $11 \mathrm{~b}$, respectively. Increasing contents of steam in $\mathrm{CO}_{2}$ decreased $\mathrm{C}_{\mathrm{p}}$ in oxy-fuel atmosphere when both 20 or 30 vol.\% of oxygen were used while the opposite trend was found for $\mathrm{N}_{2}$ atmosphere. These opposed values explicate the observed combustion behaviour in $\mathrm{CO}_{2}$ and $\mathrm{N}_{2}$ environment with 20 vol.\% of steam. When $\mathrm{H}_{2} \mathrm{O}$ concentration augmented to 40 and 70 vol.\%, clear patterns for the characteristic temperatures were not found and the variations of $\mathrm{C}_{\mathrm{p}}$ shown in Figure 11 were not enough to explain the obtained values. Other factors might be involved in the combustion process and combination of them caused the increase or decrease of the characteristic temperatures in each considered condition.

In the case of coal $\mathrm{A}$, where the decrease of $\mathrm{T}_{\mathrm{bo}}$ took place at a higher temperature range than with coals $\mathrm{B}$ and $\mathrm{C}$, the occurrence of the endothermic steam gasification reaction might play a role reducing the temperature of the coal particles $[13,34,36]$.

$$
\mathrm{C}+\mathrm{H}_{2} \mathrm{O} \rightarrow \mathrm{CO}+\mathrm{H}_{2} \quad \Delta \mathrm{H}=130 \mathrm{~kJ} / \mathrm{mol}
$$

However, the reaction products might be favourable for the combustion process owing to their lower ignition temperature. The global effect of this reaction also depends on the steam concentration. At high temperature, a second reaction could take place, the steam shift reaction:

$\mathrm{CO}+\mathrm{H}_{2} \mathrm{O} \rightarrow \mathrm{CO}_{2}+\mathrm{H}_{2} \quad \Delta \mathrm{H}=-40.9 \mathrm{~kJ} / \mathrm{mol}$

The reaction is exothermic and produces $\mathrm{H}_{2}$, which is beneficial to the reduction in the ignition delay time of the gaseous mixture around the pulverized coal and favouring burnout $[13,34]$. On the contrary, the increase of $\mathrm{T}_{\mathrm{bo}}$ in the experiments at $70 \mathrm{vol} \% \mathrm{H}_{2} \mathrm{O}$ with coals $\mathrm{B}$ and $\mathrm{C}$, where steam gasification was not favoured due to lower reaction temperatures, could suggest that high concentrations of steam might be a hindrance for coal oxidation. It has been proposed that higher thermal diffusivity and emissivity of $\mathrm{H}_{2} \mathrm{O}$ with respect to that of $\mathrm{CO}_{2}$ or $\mathrm{N}_{2}$ would favour the radiation heat transfer while coal particle temperature would be reduced, making $\mathrm{T}_{\mathrm{i}}$ and $\mathrm{T}_{\mathrm{bo}}$ larger $[13,16,34]$.

In terms of oxidation reaction rate, only coal $\mathrm{C}$ was clearly affected by the presence of steam, with an important decrease in $\mathrm{DTG}_{\max }$, in greater extent for 20 vol. $\% \mathrm{O}_{2}$ experiments. In all the studied conditions, the oxidation of coal $\mathrm{C}$ occurred in one step, consuming simultaneously the volatile fraction and the fixed carbon and involving a great demand of 
oxygen. Diffusion coefficient of oxygen in $\mathrm{H}_{2} \mathrm{O}$ is higher than in $\mathrm{N}_{2}$ or $\mathrm{CO}_{2}$, as shown in Figure 5b. Therefore, oxygen availability on particle environment is higher in an oxy-steam atmosphere under the same oxygen concentration, favouring volatile matter release and consumption and, as a consequence, leading to a higher reactivity [19] in the first stages of oxidation. Other possible mechanism of the effect of steam content on ignition of coal particles is the promotion effect of $\mathrm{OH}$ radical on the oxidation of volatile hydrocarbons [37]. Lei et al. [13] also considered that the oxidation effect of $\mathrm{H}_{2} \mathrm{O}$ is higher than $\mathrm{N}_{2}$ or $\mathrm{CO}_{2}$ to explain the beneficial effect of water on combustion.

According to the results shown above, the effect of steam on coal conversion was mainly dependent on coal rank. In order to gain insight into the different effects of steam on devolatilization and oxidation of coal, kinetic parameters were calculated and analysed in the following section.

\subsection{Combustion kinetics}

There are some attempts in literature to determine thermal reactivity and kinetics of coal in oxy-fuel combustion with isoconversional and non-isothermal thermogravimetric experiments from pyrolysis chars obtained from parent fuels [14, 15, 19]. Nevertheless, it is well stablished that even mild pyrolysis treatments for char production involve changes in particle structure, crosslinking and surface chemistry [20,38]. Moreover, volatile matter release might be favoured during direct oxidation of the fuel compared to a devolatilization/char oxidation scheme, because oxygen enhances the devolatilization and reactivity of the coal [30]. This effect should be taken into account in oxy-fuel combustion where $\mathrm{CO}_{2}$ replaces $\mathrm{N}_{2}$ and in oxy-steam combustion with important presence of $\mathrm{H}_{2} \mathrm{O}$ which might modify the devolatilization stage. Anthracite (coal A) clearly exemplified this behaviour when compared the low weight change due to volatile matter content release in devolatilization experiments (Figures 1 and 2) with the extent of mass change and DTG first peak in oxidation tests (Figures 3, 4, 8, 9). For this reason, other authors proposed using direct coal oxidation for kinetic studies in oxy-fuel [34, 39] and oxy-steam combustion [18]. However, in these works, DTG curves showed a single peak profile from which separated events of devolatilization and oxidation were not detected. The combustion reaction was considered as a multi-staged process where experimental combustion profiles were divided into several steps just in order to obtain accurate fitting of the kinetic models $[39,40]$. 
The well-defined two-peak DTG curves obtained in the present work allowed the differentiation of devolatilization and oxidation stages for coals A and B, whereas combustion of coal $\mathrm{C}$ took place in a single stage due to its high reactivity. These results should be taken into account for the kinetic calculations. In the case of coal $\mathrm{C}$, the whole range of $\alpha(0.05-$ 0.95) was considered in the application of the Coats-Redfern integral method. Lower and upper data values were not included to avoid any experimental error or distorted data. However, preliminary analysis of the combustion data obtained with coal A and coal B showed that global kinetics calculated using $\alpha$ values from 0.05 to 0.95 did not adjust the experimental data properly, despite the fact that $\mathrm{R}^{2}$ coefficient was very high for both coal $\mathrm{A}$ (0.980-0.989) and coal B (0.988-0.995). It was required to consider two different zones for kinetic determination assuring that only devolatilization or oxidation took place in the considered interval. In order to obtain devolatilization kinetics, the data range comprised between $\alpha=0.05$ and the temperature corresponding to the maximum mass loss rate in the first peak was examined (Figure 12). Oxidation kinetics was evaluated in the interval between $\mathrm{T}_{\text {peak }}$, associated to $\mathrm{DTG}_{\max }$, and $\alpha=0.95$. Kinetic parameters, i.e. activation energy and preexponential factor, were obtained for every studied condition with variable steam and oxygen concentrations in $\mathrm{N}_{2}$ or $\mathrm{CO}_{2}$ at one heating rate $(20 \mathrm{~K} / \mathrm{min})$. The values of these parameters, together with $\mathrm{R}^{2}$ and the temperature range studied, are summarized in Tables 3, 4 and 5 for coals A, B and C, respectively.

Figure 13a is a graphic representation of devolatilization and oxidation activation energies for the studied coals obtained at the main combustion conditions: conventional combustion (20\% $\left.\mathrm{O}_{2}+80 \% \mathrm{~N}_{2}\right)$, oxy-fuel combustion $\left(20 \% \mathrm{O}_{2}+80 \% \mathrm{CO}_{2}\right)$, wet-recycle oxy-fuel combustion $\left(20 \% \mathrm{O}_{2}+40 \% \mathrm{H}_{2} \mathrm{O}+40 \% \mathrm{CO}_{2}\right)$ and oxy-steam combustion $\left(20 \% \mathrm{O}_{2}+70 \% \mathrm{H}_{2} \mathrm{O}+10 \%\right.$ $\mathrm{CO} 2$ ). Figure $13 \mathrm{~b}$ illustrates the activation energies obtained in the same range of conditions with 30 vol. $\% \mathrm{O}_{2}$. As can be seen in Figure 13a, the main differences in terms of kinetic values were due to the inherent nature of each coal. Anthracite (coal A) exhibited higher $E_{a}$ values than the blended coal B, meanwhile single-step direct oxidation of highly reactive coal $\mathrm{C}$ led to $\mathrm{E}_{\mathrm{a}}$ values in the interval $73-80 \mathrm{~kJ} / \mathrm{mol}$. Liu et al [41] studied the combustion performance of three types of lignites and a bituminous coal by thermogravimetric analysis, finding that activation energy decreased with an increasing volatile matter content. In the case of coals A and B, where two distinct peaks where found in the DTG profiles, activation energies for the first peak, corresponding to devolatilization in direct oxidation, presented higher values $(148-156 \mathrm{~kJ} / \mathrm{mol}$ for coal $\mathrm{A}$ and $77-87 \mathrm{~kJ} / \mathrm{mol}$ for coal B) than those obtained 
for the second peak, i.e. oxidation, (91-97 kJ/mol for coal A and 66-71 kJ/mol for coal B). Similar results were found in previous investigations when isoconversional kinetic analyses were used to investigate coal direct oxidation [39, 42]. Activation energy was higher at first stages of coal conversion, when volatile matter is consumed, decreasing $\mathrm{E}_{\mathrm{a}}$ as conversion degree increased. The results of this work confirmed the impact of coal rank on reactivity in conventional combustion and oxy-combustion. This was as well important in oxy-steam conditions. Nevertheless, no significant differences between the apparent activation energies were obtained for each coal when comparing different combustion technologies.

The same trend for $\mathrm{E}_{\mathrm{a}}$ variation in terms of coal rank is shown in Figure 13b where activations energies for experiments with $30 \mathrm{vol} \%$ oxygen are displayed, although in this case oxygenenriched experiments involved higher $E_{a}$ values. The increase of apparent activation energy with the oxygen concentration was previously described by several authors $[15,18,43]$. This fact is related to the compensation effect between the kinetic parameters, $E_{a}$ and $A$, in kinetic calculations described in section 2.3, which implies that the increase of the apparent preexponential factor seems to attenuate the decrease of the reaction rate constant caused by the increase of the apparent activation energy [43].

It has been recently demonstrated that kinetic parameters for oxy-combustion should be determined in the low temperature range (below 900K) to ensure the chemical kinetic regime, while the reaction rate at temperatures above $1000 \mathrm{~K}$ should be determined by extrapolation based on the Arrhenius equation [44]. The temperature interval considered for the kinetics calculation is shown in Tables 3, 4 and 5 for every studied operating condition. All of them are in the range of chemical reaction control kinetics with the exception of $\mathrm{T}_{\mathrm{bo}}$ for coal $\mathrm{A}$ direct oxidation (Table 3). Using the calculated kinetic parameters, rate constant $\mathrm{k}$ can be obtained using Equation 3 and the Arrhenius relationship can be plotted extrapolating the results for higher temperatures, in the range of combustion in fluidised bed and entrained flow reactors. Figure 14 displays the obtained values for rate constant $\mathrm{k}$ in the $800-1200 \mathrm{~K}$ range, to compare oxy-steam and enriched oxy-steam combustion with the most representative combustion atmospheres. Figure 14 illustrates how oxidation rate is dependent on coal rank, presenting lower values for anthracite as a general trend, and the highest for coal C. Similar rates were obtained for all the conditions studied with coal A, although a slight increase was found in $30 \% \mathrm{O}_{2}$ combustion with respect to $20 \mathrm{vol} . \% \mathrm{O}_{2}$. Coal $\mathrm{B}$, the commercial blend, exhibited a uniform combustion behaviour, with no significant differences in reaction rate under high concentration of steam with respect to conventional combustion or oxy-fuel 
combustion, both in 20 vol. $\% \mathrm{O}_{2}$ and 30 vol. $\% \mathrm{O}_{2}$. In the case of the highly reactive coal $\mathrm{C}$, an obvious effect of the oxygen concentration was observed, with higher reaction rates at 30 vol.\% $\mathrm{O}_{2}$. Oxy-steam and enriched oxy-steam combustion show lower reaction rates than enriched conditions, but higher than conventional and oxy-fuel conditions. This suggests that steam presence promotes oxidation at $20 \mathrm{vol} . \% \mathrm{O}_{2}$ with coals that contain a high proportion of volatile matter.

According to the results shown above, this kinetic study indicates that oxy-steam combustion presents close reaction rates to those found in conventional and oxy-fuel combustion. Therefore, from an operational point of view, oxy-steam combustion is a feasible technology that allows $\mathrm{CO}_{2}$ capture overcoming some of the main oxy-fuel combustion disadvantages.

\section{Conclusions}

The devolatilization and combustion behaviour of three coals (anthracite, blend of subbituminous coals and low-rank coal) with dissimilar characteristics was investigated in a thermobalance with a water vapour furnace that allowed working at high steam concentrations. Non-isothermal experiments (423-1173 K) were carried out with variable steam concentrations $\left(0,20,40\right.$ and 70 vol.\%) in $\mathrm{N}_{2}$ and $\mathrm{CO}_{2}$ to study devolatilization performance. Combustion tests were accomplished with the same steam concentrations in $\mathrm{N}_{2}$ and $\mathrm{CO}_{2}$ under 20 and $30 \mathrm{vol} \% \mathrm{O}_{2}$ in order to compare the effect of the chemical environment on conventional, oxy-fuel and oxy-steam combustion. Kinetic parameters, i.e. activation energy $\left(\mathrm{E}_{\mathrm{a}}\right)$ and preexponential factor $(\mathrm{A})$, for devolatilization and combustion were also determined from the TG profiles using the Coats-Redfern integral method, assuming first order reactions.

The main conclusions of this work are the following:

1. Substitution of $\mathrm{N}_{2}$ by $\mathrm{CO}_{2}$ in devolatilization experiments did not affect the devolatilization behaviour of the three coals. DTG peak temperatures and reactivities did not change in the presence of high steam concentrations but were significantly influenced by the coal rank. $E_{a}$ values for devolatilization reaction were very low $(26.7-47.5 \mathrm{~kJ} / \mathrm{mol})$ in comparison with data from literature and followed the next trend: $E_{a}$ in $N_{2}>E_{a}$ in oxysteam $>\mathrm{E}_{\mathrm{a}}$ in $\mathrm{CO}_{2}$.

2. DTG curves of coals $A$ and B obtained from direct oxidation experiments showed a double peak that allowed the independent study of the devolatilization and oxidation 
stages while the most reactive coal C presented an only DTG peak. Characteristic temperatures and maximum reaction rates were determined as a function of $\mathrm{H}_{2} \mathrm{O}$ partial pressure for the three coals.

3. Replacing $\mathrm{CO}_{2}$ with $20 \% \mathrm{H}_{2} \mathrm{O}$ produced a decrease in ignition and burnout temperatures due to the lower specific heat capacity of $\mathrm{H}_{2} \mathrm{O}$ for all the conditions studied. At higher steam concentrations, coals showed different behaviours depending mainly on their rank. For high-rank anthracite, burnout temperatures decreased in oxidation with $40 \%$ and $70 \%$ $\mathrm{H}_{2} \mathrm{O}$, suggesting that gasification at high temperature favoured the oxidation process on particle surface. For high-volatile content coals, $40 \%$ and $70 \% \mathrm{H}_{2} \mathrm{O}$ enhanced direct oxidation rate due to higher $\mathrm{O}_{2}$ diffusivity in $\mathrm{H}_{2} \mathrm{O}$ than in $\mathrm{CO}_{2}$ or $\mathrm{N}_{2}$.

4. Kinetic parameters were determined independently for devolatilization and oxidation stages from selected intervals of the TG-DTG curves. Activation energy was higher at first stages of coal conversion, when volatile matter was consumed, while lower values were calculated for the oxidation reaction. Significant differences between the apparent activation energies were not found for the three coals when comparing different combustion technologies.

5. Arrhenius dependency of the reaction rate constant at high temperature (800-1200K) was calculated. When comparing conventional, oxy-fuel and oxy-steam combustion technologies, no differences were observed for sub-bituminous coal and anthracite. Only the low-rank coal showed that reaction rate in oxy-steam was between those calculated for $30 \% \mathrm{O}_{2}$ oxy-fuel and $20 \%$ oxy-fuel and air combustion. This seems to indicate that steam presence promotes oxidation at $20 \% \mathrm{O}_{2}$ when working with high-volatile-matter content coals.

\section{Acknowledgements}

This work was funded by the Spanish Ministry of Economy, Industry and Competitiveness under contracts ENE2015-67448-C2-1 and ENE2015-67448-C2-2-R. A.I. Escudero acknowledges the FPI fellowship BES-2016-078573 financed by the Spanish Ministry of Economy, Industry and Competitiveness. 


\section{References}

[1] International Energy Agency. Technology Roadmap: Carbon capture and storage. In: https://www.iea.org/publications/freepublications/publication/TechnologyRoadmapCa rbonCaptureandStorage.pdf, ed. Paris, France; 2013:63.

[2] Chen L, Yong SZ, Ghoniem AF. Oxy-fuel combustion of pulverized coal: Characterization, fundamentals, stabilization and CFD modeling. Progress in Energy and Combustion Science 2012;38(2):156-214.

[3] Stanger R, Wall T, Spörl R, Paneru M, Grathwohl S, Weidmann M, et al. Oxyfuel combustion for $\mathrm{CO}_{2}$ capture in power plants. International Journal of Greenhouse Gas Control 2015;40:55-125.

[4] Lockwood T. Development in oxyfuel combustion of coal. In: CCC/240, ed. London: IEA Clean Coal Centre; 2014:122.

[5] Hagi H, Nemer M, Le Moullec Y, Bouallou C. Towards Second Generation Oxypulverized Coal Power Plants: Energy Penalty Reduction Potential of Pressurized Oxy-combustion Systems. Energy Procedia 2014;63:431-9.

[6] Zayoud A, Mahanta P, Saha UK. Pure oxy-fuel circulating fluidized bed combustion by controlling adiabatic flame temperature using fuel staging. Current Science (00113891) 2017;113(8):1560-7.

[7] Seepana S, Jayanti S. Steam-moderated oxy-fuel combustion. Energy Conversion and Management 2010;51(10):1981-8.

[8] Zanganeh K, Salvador C, Mitrovic M, Shafeen A. 3rd generation oxy-fuel combustion systems. 3rd IEAGHG International Oxy-Combustion Workshop. Yokohama, Japan; 2008.

[9] Salvador C, Mitrovic M, Zanganeh K. Novel oxy-steam burner for zero-emission power plants. 1st Oxyfuel Combustion Conference. Cottbus, Germany; 2009.

[10] Sheng L, Liu X, Si J, Xu Y, Zhou Z, Xu M. Simulation and comparative exergy analyses of oxy-steam combustion and $\mathrm{O}_{2} / \mathrm{CO}_{2}$ recycled combustion pulverized-coalfired power plants. International Journal of Greenhouse Gas Control 2014;27:267-78. 
[11] Tu Y, Liu H, Su K, Chen S, Liu Z, Zheng C, et al. Numerical study of $\mathrm{H}_{2} \mathrm{O}$ addition effects on pulverized coal oxy-MILD combustion. Fuel Processing Technology 2015; 138:252-62.

[12] Jin B, Zhao H, Zou C, Zheng C. Comprehensive investigation of process characteristics for oxy-steam combustion power plants. Energy Conversion and Management 2015;99:92-101.

[13] Lei K, Ye B, Cao J, Zhang R, Liu D. Combustion Characteristics of Single Particles from Bituminous Coal and Pine Sawdust in $\mathrm{O}_{2} / \mathrm{N}_{2}, \mathrm{O}_{2} / \mathrm{CO}_{2}$, and $\mathrm{O}_{2} / \mathrm{H}_{2} \mathrm{O}$ Atmospheres. Energies 2017;10(11):1695.

[14] Gil MV, Riaza J, Álvarez L, Pevida C, Pis JJ, Rubiera F. A study of oxy-coal combustion with steam addition and biomass blending by thermogravimetric analysis. Journal of Thermal Analysis and Calorimetry 2012;109(1):49-55.

[15] Yi B, Zhang L, Huang F, Mao Z, Zheng C. Effect of $\mathrm{H}_{2} \mathrm{O}$ on the combustion characteristics of pulverized coal in $\mathrm{O}_{2} / \mathrm{CO}_{2}$ atmosphere. Applied Energy 2014;132(Supplement C):349-57.

[16] Riaza J, Álvarez L, Gil MV, Pevida C, Pis JJ, Rubiera F. Effect of oxy-fuel combustion with steam addition on coal ignition and burnout in an entrained flow reactor. Energy 2011;36(8):5314-9.

[17] Cai L, Zou C, Guan Y, Jia H, Zhang L, Zheng C. Effect of steam on ignition of pulverized coal particles in oxy-fuel combustion in a drop tube furnace. Fuel 2016;182:958-66.

[18] Zou C, Zhang L, Cao S, Zheng C. A study of combustion characteristics of pulverized coal in $\mathrm{O}_{2} / \mathrm{H}_{2} \mathrm{O}$ atmosphere. Fuel 2014;115(Supplement C):312-20.

[19] Zhang L, Zou C, Wu D, Liu Y, Zheng C. A study of coal chars combustion in $\mathrm{O}_{2} / \mathrm{H}_{2} \mathrm{O}$ mixtures by thermogravimetric analysis. Journal of Thermal Analysis and Calorimetry 2016;126(2):995-1005.

[20] Xu J, Su S, Sun Z, Qing M, Xiong Z, Wang Y, et al. Effects of steam and $\mathrm{CO}_{2}$ on the characteristics of chars during devolatilization in oxy-steam combustion process. Applied Energy 2016;182(Supplement C):20-8.

[21] Escudero A, Espatolero S, Mayoral M, Andrés J, Blanco S, Fernández J, et al. Towards oxy-steam combustion: the effect of increasing the steam concentration in 
oxy-coal-fired reactors. 2nd International Workshop on Oxy-Fuel Combustion. Bochum, Germany; 2018.

[22] Li Q, Zhao C, Chen X, Wu W, Li Y. Comparison of pulverized coal combustion in air and in $\mathrm{O} 2 / \mathrm{CO} 2$ mixtures by thermo-gravimetric analysis. Journal of Analytical and Applied Pyrolysis 2009;85(1):521-8.

[23] Niu SL, Lu CM, Han KH, Zhao JL. Thermogravimetric analysis of combustion characteristics and kinetic parameters of pulverized coals in oxy-fuel atmosphere. Journal of Thermal Analysis and Calorimetry 2009;98(1):267.

[24] Czajka K, Kisiela A, Moroń W, Ferens W, Rybak W. Pyrolysis of solid fuels: Thermochemical behaviour, kinetics and compensation effect. Fuel Processing Technology 2016;142(Supplement C):42-53.

[25] Güneş M, Güneş S. A Study on Thermal Decomposition Kinetics of Some Turkish Coals. Energy Sources 2005;27(8):749-59.

[26] Toloue Farrokh N, Askari M, Fabritius T. Investigation of Tabas anthracite coal devolatilization: Kinetics, char structure and major evolved species. Thermochimica Acta 2017;654:74-80.

[27] Chen C, Wang J, Liu W, Zhang S, Yin J, Luo G, et al. Effect of pyrolysis conditions on the char gasification with mixtures of $\mathrm{CO}_{2}$ and $\mathrm{H}_{2} \mathrm{O}$. Proceedings of the Combustion Institute 2013;34(2):2453-60.

[28] Mu L, Chen J, Yin H, Song X, Li A, Chi X. Pyrolysis behaviors and kinetics of refining and chemicals wastewater, lignite and their blends through TGA. Bioresource Technology 2015;180:22-31.

[29] Valdés CF, Marrugo G, Chejne F, Román JD, Montoya JI. Effect of atmosphere reaction and heating rate on the devolatilization of a Colombian sub-bituminous coal. Journal of Analytical and Applied Pyrolysis 2016;121:93-101.

[30] Biagini E, Tognotti L. A generalized correlation for coal devolatilization kinetics at high temperature. Fuel Processing Technology 2014;126(Supplement C):513-20.

[31] Deng J, Li Q, Xiao Y, Wen H. The effect of oxygen concentration on the nonisothermal combustion of coal. Thermochimica Acta 2017;653:106-15. 
[32] Meng F, Yu J, Tahmasebi A, Han Y. Pyrolysis and Combustion Behavior of Coal Gangue in $\mathrm{O}_{2} / \mathrm{CO}_{2}$ and $\mathrm{O}_{2} / \mathrm{N}_{2}$ Mixtures Using Thermogravimetric Analysis and a Drop Tube Furnace. Energy \& Fuels 2013;27(6):2923-32.

[33] Yuan Y, Li S, Xu Y, Yao Q. Experimental and theoretical analyses on ignition and surface temperature of dispersed coal particles in $\mathrm{O}_{2} / \mathrm{N}_{2}$ and $\mathrm{O}_{2} / \mathrm{CO}_{2}$ ambients. Fuel 2017;201:93-8.

[34] Zou C, Cai L, Wu D, Liu Y, Liu S, Zheng C. Ignition behaviors of pulverized coal particles in $\mathrm{O}_{2} / \mathrm{N}_{2}$ and $\mathrm{O}_{2} / \mathrm{H}_{2} \mathrm{O}$ mixtures in a drop tube furnace using flame monitoring techniques. Proceedings of the Combustion Institute 2015;35(3):3629-36.

[35] Cai L, Zou C, Liu Y, Zhou K, Han Q, Zheng C. Numerical and experimental studies on the ignition of pulverized coal in $\mathrm{O}_{2} / \mathrm{H}_{2} \mathrm{O}$ atmospheres. Fuel 2015;139:198-205.

[36] Cai L, Zou C. Oxy-steam Combustion. In: Zeng Chuguang LZ, editor Oxy-Fuel Combustion Fundamentals, Theory and Practive. United Kingdom: Elsevier; 2018, p. 325-38.

[37] Xu Y, Li S, Yao Q, Yuan Y. Investigation of steam effect on ignition of dispersed coal particles in $\mathrm{O}_{2} / \mathrm{N}_{2}$ and $\mathrm{O}_{2} / \mathrm{CO}_{2}$ ambiences. 2nd International Workshop on Oxy-Fuel Combustion. Bochum, Germany; 2018.

[38] Senneca O, Scala F, Chirone R, Salatino P. Relevance of structure, fragmentation and reactivity of coal to combustion and oxy-combustion. Fuel 2017;201:65-80.

[39] Zhou Z, Hu X, You Z, Wang Z, Zhou J, Cen K. Oxy-fuel combustion characteristics and kinetic parameters of lignite coal from thermo-gravimetric data. Thermochimica Acta 2013;553:54-9.

[40] Li H, Xia S, Ma P. Thermogravimetric investigation of the co-combustion between the pyrolysis oil distillation residue and lignite. Bioresource Technology 2016;218:61522.

[41] Liu MQ, Liu JZ, Yu YJ, Wang ZH, Zhou JH, Cen KF. Investigation of Lignite Combustion Characteristics with Thermal Analysis. Advanced Materials Research 2013;614-615:25-30.

[42] Slyusarskiy KV, Larionov KB, Osipov VI, Yankovsky SA, Gubin VE, Gromov AA. Non-isothermal kinetic study of bituminous coal and lignite conversion in air and in argon/air mixtures. Fuel 2017;191:383-92. 
[43] Wang Ca, Zhang X, Liu Y, Che D. Pyrolysis and combustion characteristics of coals in oxyfuel combustion. Applied Energy 2012;97:264-73.

[44] Babinski P, Sciazko M, Ksepko E. Limitation of thermogravimetry for oxycombustion analysis of coal chars. Journal of Thermal Analysis and Calorimetry 2017. 
Table 1. Proximate and ultimate analysis of the tested coals.

\begin{tabular}{lccc}
\hline & Coal A & Coal B & Coal C \\
\hline Moisture (\%, a.r.) & 1.8 & 5.9 & 11.2 \\
Ash (\%, dry) & 26.9 & 27.8 & 4.2 \\
Volatile (\%, dry) & 5.5 & 26.4 & 49.4 \\
Fixed Carbon (\%, dry) & 67.6 & 45.8 & 46.4 \\
\hline C (\%) & 66.7 & 50.0 & 63.8 \\
H (\%) & 1.69 & 3.5 & 5.4 \\
N (\%) & 0.87 & 1.1 & 1.0 \\
S (\%) & 0.87 & 4.5 & 0.1 \\
\hline LHV (MJ/kg, dry) & 23.6 & 20.16 & 25.66 \\
\hline
\end{tabular}


Table 2. Kinetic parameters for devolatilization reaction with coal B and coal C.

\begin{tabular}{ccccccccc}
\hline & & & \multicolumn{3}{c}{ Coal $\mathbf{B}$} & \multicolumn{3}{c}{ Coal C } \\
\cline { 3 - 9 } \% $\mathbf{H}_{2} \mathbf{O}$ & $\boldsymbol{\%}_{\mathbf{2}}$ & \% $\mathbf{C O}_{\mathbf{2}}$ & $\begin{array}{c}\mathbf{E}_{\mathbf{a}} \\
(\mathbf{k J} / \mathbf{m o l})\end{array}$ & $\begin{array}{c}\mathbf{A} \\
\left(\mathbf{m i n}^{-\mathbf{1}}\right)\end{array}$ & $\mathbf{R}^{\mathbf{2}}$ & $\begin{array}{c}\mathbf{E}_{\mathbf{a}} \\
(\mathbf{k J} \mathbf{m} \mathbf{m o l})\end{array}$ & $\begin{array}{c}\mathbf{A} \\
\left(\mathbf{m i n}^{-\mathbf{1}}\right)\end{array}$ & $\mathbf{R}^{\mathbf{2}}$ \\
\hline 0 & 100 & 0 & 41.3 & 78.3 & 0.988 & 47.5 & 357.5 & 0.997 \\
20 & 80 & 0 & 30.8 & 6.3 & 0.989 & 38.0 & 28.8 & 0.993 \\
40 & 60 & 0 & 29.8 & 4.9 & 0.989 & 39.0 & 37.5 & 0.992 \\
70 & 30 & 0 & 27.9 & 3.2 & 0.985 & 38.9 & 36.4 & 0.992 \\
\hline 0 & 0 & 100 & 26.7 & 2.8 & 0.955 & 39.2 & 36.9 & 0.994 \\
20 & 0 & 80 & 32.7 & 8.4 & 0.984 & 38.2 & 28.7 & 0.994 \\
40 & 0 & 60 & 37.7 & 21.8 & 0.995 & 42.1 & 68.2 & 0.986 \\
70 & 0 & 30 & 32.4 & 7.4 & 0.989 & 40.9 & 53.5 & 0.992 \\
\hline
\end{tabular}


Table 3. Kinetic parameters for combustion of coal A.

\begin{tabular}{|c|c|c|c|c|c|c|c|c|c|c|c|c|c|}
\hline \multirow[b]{2}{*}{$\% \mathrm{O}_{2}$} & \multirow[b]{2}{*}{$\% \mathrm{H}_{2} \mathrm{O}$} & \multirow[b]{2}{*}{$\% \mathrm{CO}_{2}$} & \multirow[b]{2}{*}{$\% \mathrm{~N}_{2}$} & \multicolumn{5}{|c|}{ Devolatilization } & \multicolumn{5}{|c|}{ Oxidation } \\
\hline & & & & $\begin{array}{c}\mathbf{E}_{\mathrm{a}} \\
(\mathrm{kJ} / \mathrm{mol})\end{array}$ & $\begin{array}{c}\mathbf{A} \\
\left(\mathbf{m i n}^{-1}\right)\end{array}$ & $\mathbf{R}^{2}$ & $\begin{array}{l}\mathbf{T}_{\mathbf{0}} \\
(\mathbf{K})\end{array}$ & $\begin{array}{l}T_{1} \\
(K)\end{array}$ & $\begin{array}{c}\mathbf{E}_{\mathrm{a}} \\
(\mathrm{kJ} / \mathrm{mol})\end{array}$ & $\begin{array}{c}\mathbf{A} \\
\left(\mathbf{m i n}^{-1}\right)\end{array}$ & $\mathbf{R}^{2}$ & $\begin{array}{c}\mathbf{T}_{\mathbf{0}} \\
(\mathbf{K})\end{array}$ & $\begin{array}{c}\mathbf{T}_{1} \\
(\mathbf{K})\end{array}$ \\
\hline 20 & 0 & 80 & 0 & 152.7 & $6.01 \cdot 10^{8}$ & 0.999 & 774.7 & 830.6 & 94.1 & $7.54 \cdot 10^{4}$ & 0.996 & 915.1 & 980.2 \\
\hline 20 & 20 & 60 & 0 & 169.2 & $7.88 \cdot 10^{9}$ & 0.997 & 778.8 & 834.4 & 92.6 & $6.79 \cdot 10^{4}$ & 0.999 & 894.9 & 972.0 \\
\hline 20 & 40 & 40 & 0 & 148.5 & $3.45 \cdot 10^{9}$ & 0.998 & 772.3 & 844.1 & 91.7 & $6.16 \cdot 10^{4}$ & 0.999 & 897 & 970.4 \\
\hline 20 & 70 & 10 & 0 & 156.3 & $1.13 \cdot 10^{9}$ & 0.999 & 774.5 & 844.4 & 92.6 & $7.73 \cdot 10^{4}$ & 0.998 & 889.1 & 964.0 \\
\hline 30 & 0 & 70 & 0 & 174.9 & $2.48 \cdot 10^{10}$ & 0.998 & 772.7 & 824.6 & 114.6 & $1.77 \cdot 10^{6}$ & 0.996 & 904.8 & 954.5 \\
\hline 30 & 20 & 50 & 0 & 155.2 & $1.67 \cdot 10^{9}$ & 0.999 & 758.3 & 814.7 & 105.9 & $6.45 \cdot 10^{5}$ & 0.999 & 890.8 & 943.3 \\
\hline 30 & 40 & 30 & 0 & 158.3 & $2.53 \cdot 10^{9}$ & 0.999 & 761.2 & 818.9 & 98.7 & $2.41 \cdot 10^{5}$ & 1.000 & 882.7 & 941.9 \\
\hline 30 & 70 & 0 & 0 & 156.0 & $1.57 \cdot 10^{9}$ & 0.999 & 764.0 & 824.8 & 109.0 & $1.03 \cdot 10^{6}$ & 0.999 & $884 . .9$ & 940.4 \\
\hline 20 & 0 & 0 & 80 & 148.7 & $3.99 \cdot 10^{8}$ & 0.999 & 765.5 & 824.3 & 97.0 & $1.28 \cdot 10^{5}$ & 0.999 & 900.8 & 968.6 \\
\hline 30 & 0 & 0 & 70 & 170.0 & $1.59 \cdot 10^{10}$ & 0.999 & 761.4 & 810.4 & 107.4 & $7.65 \cdot 10^{5}$ & 0.998 & 892.8 & 948.4 \\
\hline
\end{tabular}


Table 4. Kinetic parameters for combustion of coal B.

\begin{tabular}{|c|c|c|c|c|c|c|c|c|c|c|c|c|c|}
\hline \multirow[b]{2}{*}{$\% \mathrm{O}_{2}$} & \multirow[b]{2}{*}{$\% \mathrm{H}_{2} \mathrm{O}$} & \multirow[b]{2}{*}{$\% \mathrm{CO}_{2}$} & \multirow[b]{2}{*}{$\% \mathrm{~N}_{2}$} & \multicolumn{5}{|c|}{ Devolatilization } & \multicolumn{5}{|c|}{ Oxidation } \\
\hline & & & & $\begin{array}{c}\mathbf{E}_{\mathrm{a}} \\
(\mathrm{kJ} / \mathrm{mol})\end{array}$ & $\begin{array}{c}\mathbf{A} \\
\left(\min ^{-1}\right)\end{array}$ & $\mathbf{R}^{2}$ & $\begin{array}{l}\mathbf{T}_{\mathbf{0}} \\
(\mathbf{K})\end{array}$ & $\begin{array}{c}\mathbf{T}_{1} \\
(\mathbf{K})\end{array}$ & $\begin{array}{c}\mathbf{E}_{\mathrm{a}} \\
(\mathrm{kJJ} / \mathbf{m o l})\end{array}$ & $\begin{array}{c}\mathbf{A} \\
\left(\min ^{-1}\right)\end{array}$ & $\mathbf{R}^{2}$ & $\begin{array}{c}\mathbf{T}_{\mathbf{0}} \\
(\mathbf{K})\end{array}$ & $\begin{array}{l}\mathbf{T}_{1} \\
(\mathbf{K})\end{array}$ \\
\hline 20 & 0 & 80 & 0 & 77.6 & $1.20 \cdot 10^{5}$ & 1.000 & 608.2 & 667.5 & 71.2 & $2.15 \cdot 10^{4}$ & 0.999 & 778.1 & 834.2 \\
\hline 20 & 20 & 60 & 0 & 87.5 & $8.70 \cdot 10^{5}$ & 0.998 & 611.9 & 673.3 & 69.4 & $1.80 \cdot 10^{4}$ & 0.998 & 767.5 & 828.0 \\
\hline 20 & 40 & 40 & 0 & 82.1 & $2.93 \cdot 10^{5}$ & 1.000 & 610.8 & 666.2 & 67.0 & $1.14 \cdot 10^{4}$ & 0.999 & 771.5 & 833.6 \\
\hline 20 & 70 & 10 & 0 & 87.2 & $6.39 \cdot 10^{5}$ & 1.000 & 619.8 & 683.6 & 66.5 & $1.02 \cdot 10^{4}$ & 0.998 & 775.4 & 835.3 \\
\hline 30 & 0 & 70 & 0 & 85.7 & $7.81 \cdot 10^{5}$ & 0.999 & 603.0 & 660.0 & 63.6 & $7.76 \cdot 10^{3}$ & 0.990 & 757.1 & 823.2 \\
\hline 30 & 20 & 50 & 0 & 82.3 & $4.10 \cdot 10^{5}$ & 0.998 & 601.3 & 649.8 & 71.9 & $3.55 \cdot 10^{4}$ & 0.999 & 750.2 & 808.9 \\
\hline 30 & 40 & 30 & 0 & 80.8 & $2.83 \cdot 10^{5}$ & 1.000 & 602.2 & 663.9 & 67.0 & $1.47 \cdot 10^{4}$ & 0.998 & 752.9 & 815.3 \\
\hline 30 & 70 & 0 & 0 & 79.2 & $1.91 \cdot 10^{5}$ & 1.000 & 605.1 & 676.6 & 61.6 & $5.66 \cdot 10^{3}$ & 0.988 & 757.0 & 823.0 \\
\hline 20 & 0 & 0 & 80 & 80.4 & $2.62 \cdot 10^{5}$ & 1.000 & 601.2 & 660.9 & 69.2 & $1.81 \cdot 10^{4}$ & 0.998 & 766.8 & 825.3 \\
\hline 20 & 20 & 0 & 60 & 82.3 & $2.89 \cdot 10^{5}$ & 1.000 & 611.5 & 674.4 & 72.6 & $2.93 \cdot 10^{4}$ & 0.997 & 779.0 & 828.7 \\
\hline 20 & 40 & 0 & 40 & 79.1 & $1.54 \cdot 10^{5}$ & 1.000 & 609.7 & 677.3 & 69.5 & $1.72 \cdot 10^{4}$ & 0.998 & 772.7 & 832.3 \\
\hline 20 & 70 & 0 & 10 & 79.0 & $1.43 \cdot 10^{5}$ & 1.000 & 613.0 & 680.7 & 69.9 & $1.83 \cdot 10^{4}$ & 0.999 & 773.5 & 831.0 \\
\hline 30 & 0 & 0 & 70 & 84.8 & $6.33 \cdot 10^{5}$ & 0.999 & 601.4 & 663.6 & 76.1 & $6.85 \cdot 10^{4}$ & 0.998 & 756.5 & 810.7 \\
\hline 30 & 20 & 0 & 50 & 85.9 & $7.77 \cdot 10^{5}$ & 1.000 & 602.9 & 661.9 & 70.0 & $2.50 \cdot 10^{4}$ & 0.996 & 756.1 & 812.1 \\
\hline 30 & 40 & 0 & 30 & 80.3 & $2.31 \cdot 10^{5}$ & 1.000 & 606.4 & 673.0 & 68.8 & $1.95 \cdot 104$ & 0.998 & 756.5 & 816.4 \\
\hline 30 & 70 & 0 & 0 & 83.1 & $3.99 \cdot 10^{5}$ & 1.000 & 605.0 & 670.7 & 62.5 & $6.57 \cdot 10^{3}$ & 0.990 & 758.4 & 821.9 \\
\hline
\end{tabular}


Table 5. Kinetic parameters for combustion of coal C.

\begin{tabular}{ccccccccc}
\hline$\% \mathbf{O}_{\mathbf{2}}$ & $\% \mathbf{H}_{\mathbf{2}} \mathbf{O}$ & $\% \mathbf{C O}_{\mathbf{2}}$ & $\boldsymbol{\%}_{\mathbf{2}}$ & $\begin{array}{c}\mathbf{E}_{\mathbf{a}} \\
(\mathbf{k J} \mathbf{J} \mathbf{m o l})\end{array}$ & $\begin{array}{c}\mathbf{A} \\
\left(\mathbf{m i n}^{-1}\right)\end{array}$ & $\mathbf{R}^{2}$ & $\begin{array}{c}\mathbf{T}_{\mathbf{0}} \\
(\mathbf{K})\end{array}$ & $\begin{array}{c}\mathbf{T}_{\mathbf{1}} \\
(\mathbf{K})\end{array}$ \\
\hline 20 & 0 & 80 & 0 & 73.5 & $2.09 \cdot 10^{5}$ & 0.999 & 558.4 & 726.1 \\
20 & 20 & 60 & 0 & 81.3 & $1.30 \cdot 10^{6}$ & 0.997 & 558.9 & 710.8 \\
20 & 40 & 40 & 0 & 79.1 & $6.35 \cdot 10^{5}$ & 0.996 & 558.6 & 719.2 \\
20 & 70 & 10 & 0 & 80.2 & $8.94 \cdot 10^{5}$ & 0.995 & 557.0 & 716.3 \\
\hline 30 & 0 & 70 & 0 & 86.8 & $3.75 \cdot 10^{6}$ & 0.994 & 561.0 & 711.1 \\
30 & 20 & 50 & 0 & 80.9 & $1.16 \cdot 10^{6}$ & 0.995 & 554.3 & 710.6 \\
30 & 40 & 30 & 0 & 81.7 & $1.64 \cdot 10^{6}$ & 0.992 & 551.0 & 706.4 \\
30 & 70 & 0 & 0 & 80.4 & $1.05 \cdot 10^{6}$ & 0.992 & 555.0 & 710.3 \\
\hline 20 & 0 & 0 & 80 & 77.9 & $5.66 \cdot 10^{5}$ & 0.996 & 558.5 & 721.7 \\
\hline 30 & 0 & 0 & 70 & 88.2 & $6.95 \cdot 10^{6}$ & 0.981 & 556.0 & 700.8 \\
\hline
\end{tabular}




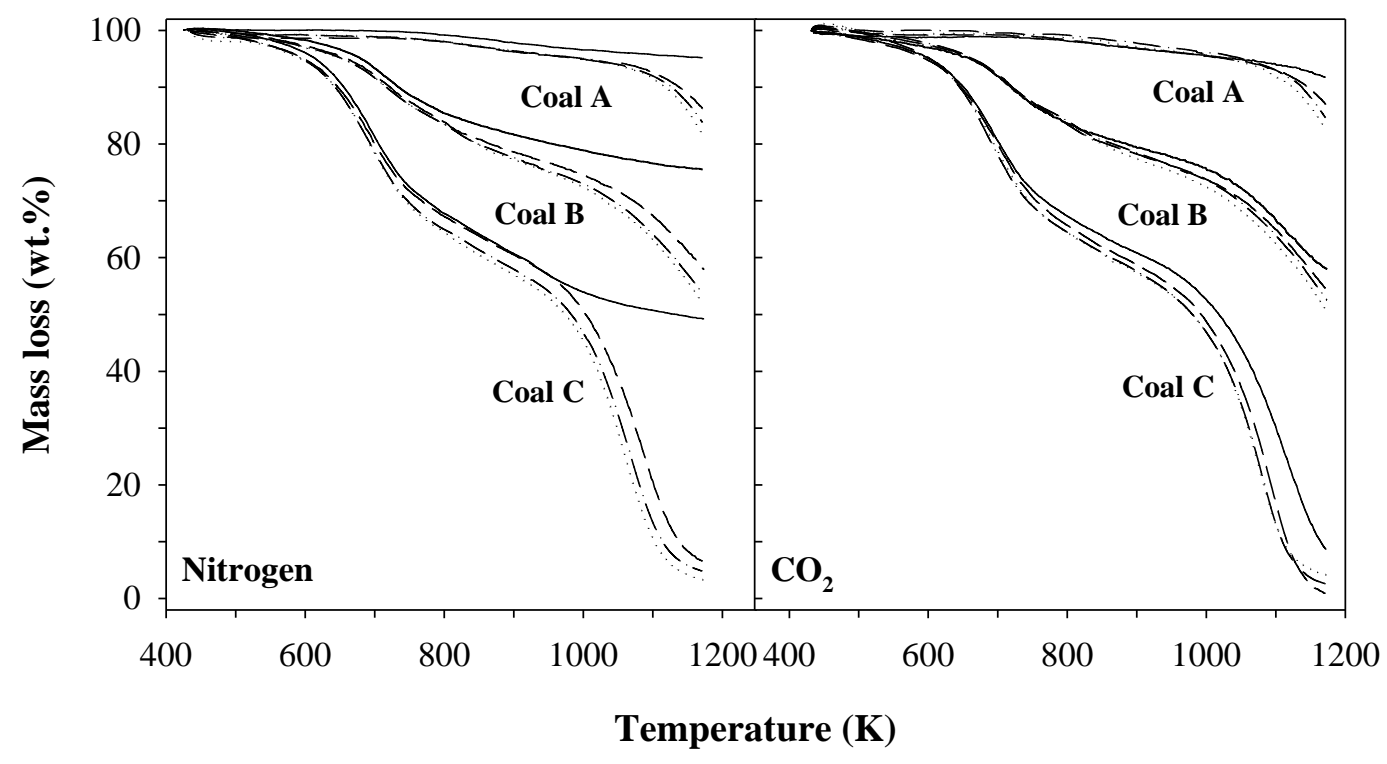

Figure 1. TG curves of devolatilization experiments with coals $\mathrm{A}, \mathrm{B}$ and $\mathrm{C}$ under different reaction atmospheres with variable water concentrations. 0 vol. $\% \mathrm{H}_{2} \mathrm{O} ; \ldots$ _ _ 20 vol. \% $\mathrm{H}_{2} \mathrm{O} ; \ldots . . .40$ vol. $\% \mathrm{H}_{2} \mathrm{O} ; \ldots \ldots . . .70$ vol. $\%$ $\mathrm{H}_{2} \mathrm{O}$ 


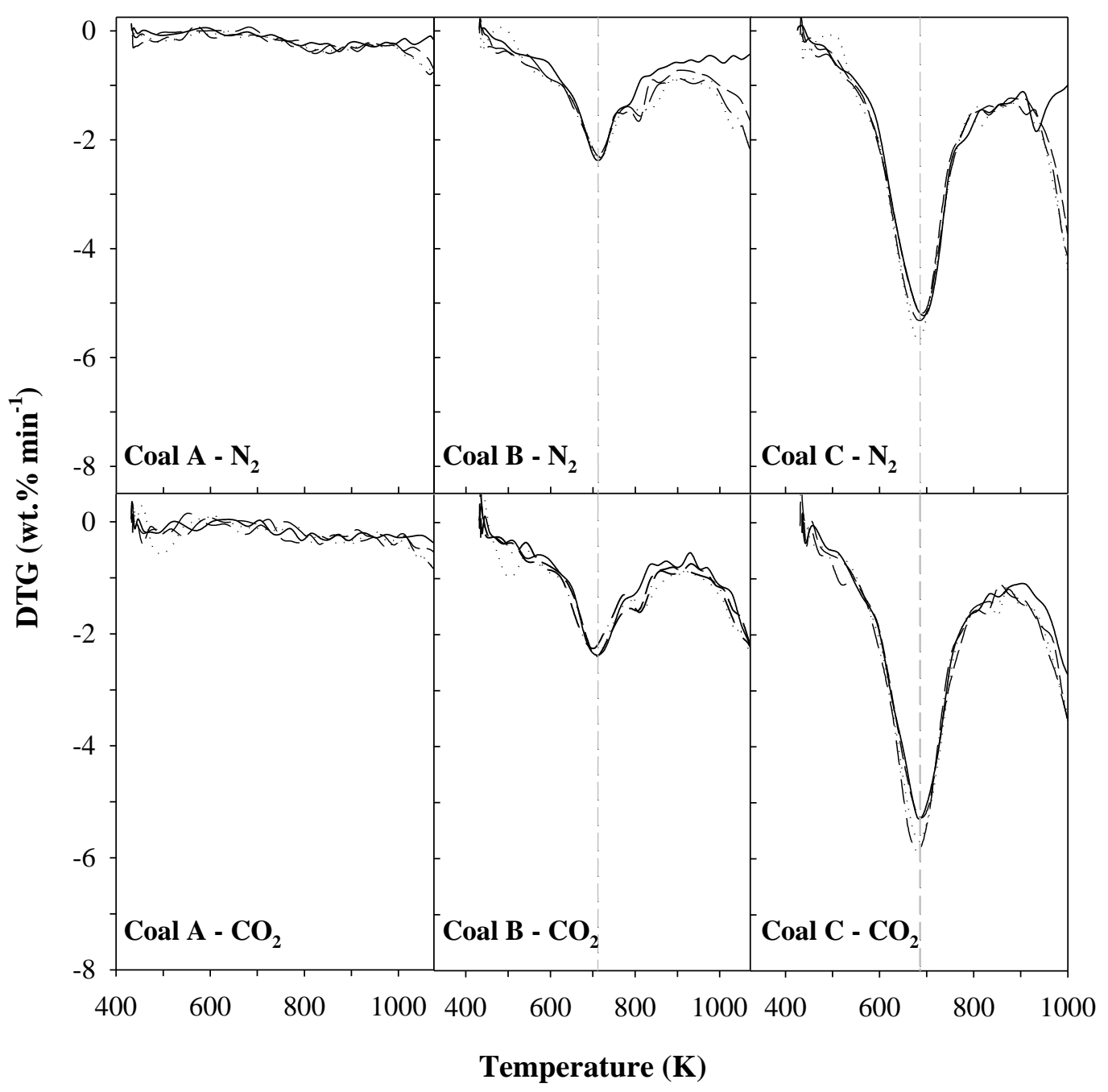

Figure 2. DTG curves of devolatilization experiments with coals $\mathrm{A}, \mathrm{B}$ and $\mathrm{C}$ under different reaction

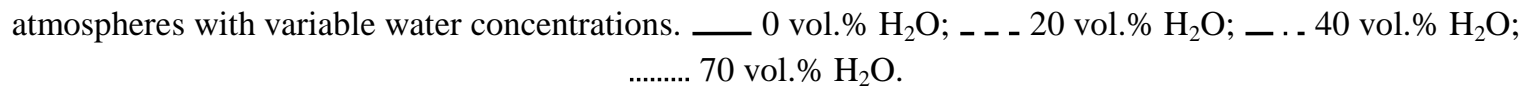




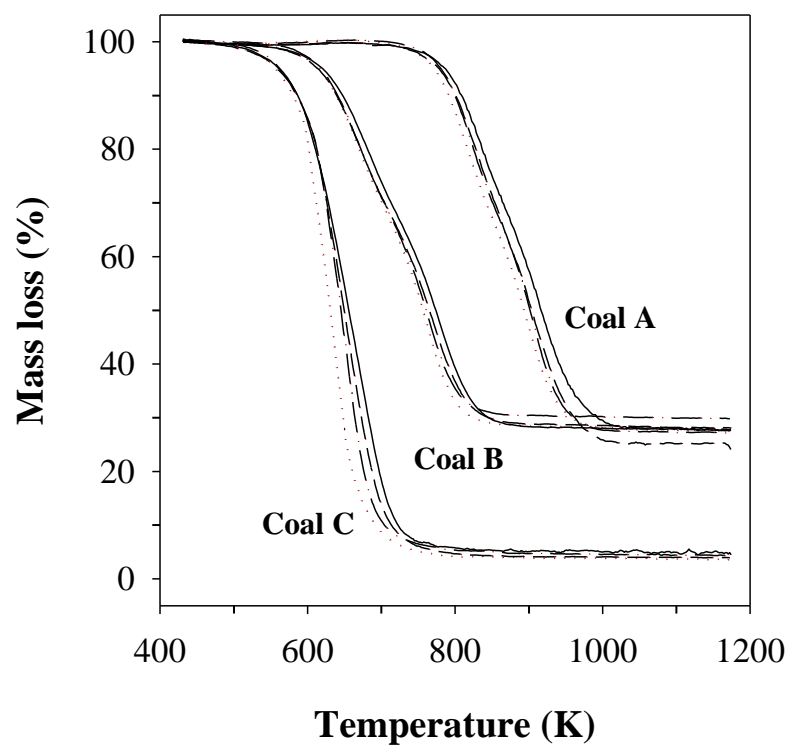

Figure 3. TG curves of combustion experiments with coals $\mathrm{A}, \mathrm{B}$ and $\mathrm{C}$ under different reaction atmospheres with variable oxygen concentrations in $\mathrm{N}_{2}$ and $\mathrm{CO}_{2}$. _ 20 vol. $\% \mathrm{O}_{2}+\mathrm{CO}_{2} ; \ldots$ _. 20 vol. $\% \mathrm{O}_{2}+\mathrm{N}_{2} ;$ _ . . 30 vol.\% $\mathrm{O}_{2}+\mathrm{CO}_{2} ; \ldots \ldots . . .30$ vol. $\% \mathrm{O}_{2}+\mathrm{N}_{2}$ 


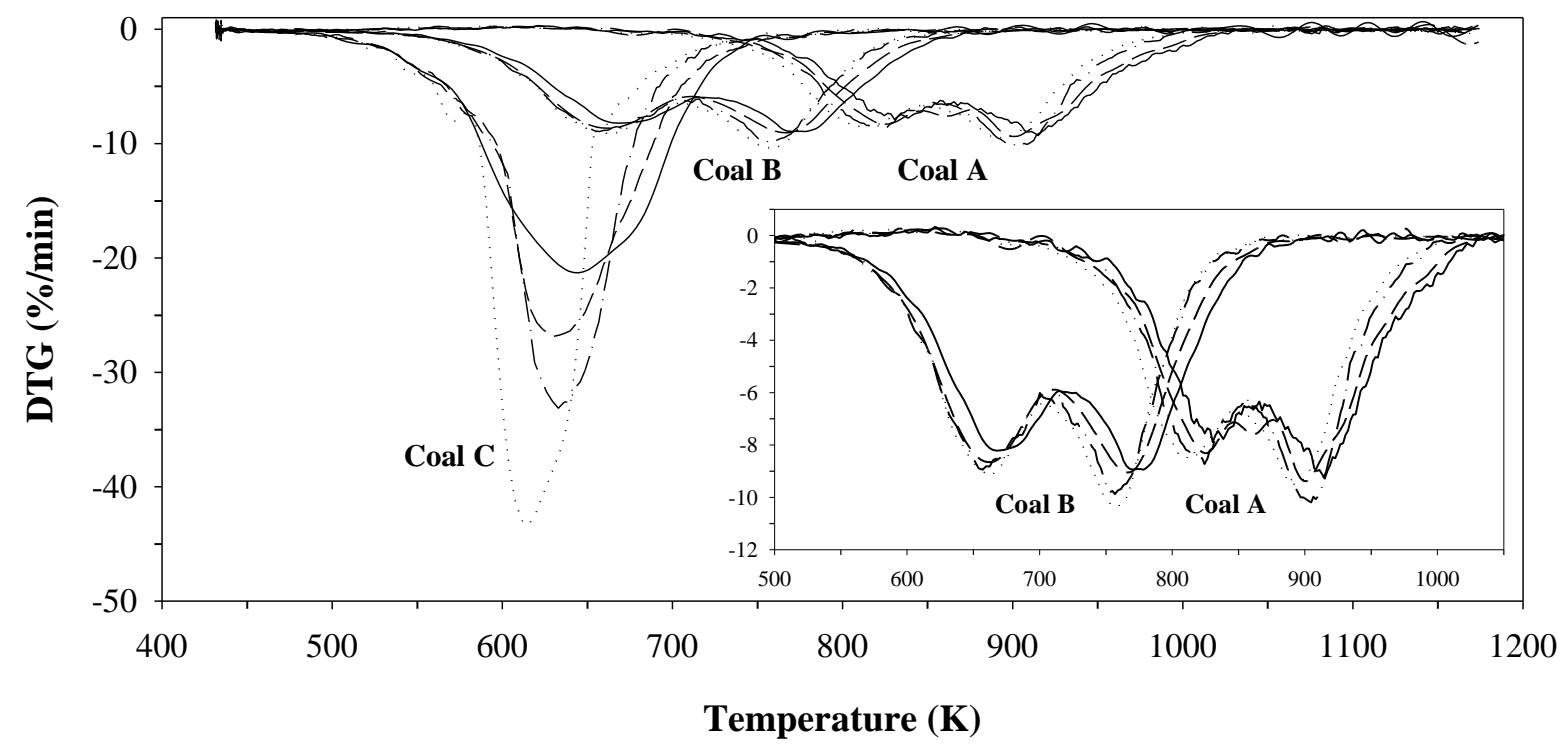

Figure 4. DTG curves of combustion experiments with coals A, B and $\mathrm{C}$ under different reaction atmospheres with variable oxygen concentrations in $\mathrm{N}_{2}$ and $\mathrm{CO}_{2}$. 20 vol. $\% \mathrm{O}_{2}+\mathrm{CO}_{2} ; \ldots .20$ vol. $\% \mathrm{O}_{2}+\mathrm{N}_{2} ; \ldots . .30$ vol. $\% \mathrm{O}_{2}+\mathrm{CO}_{2} ; \ldots \ldots . . .30$ vol. $\% \mathrm{O}_{2}+\mathrm{N}_{2}$ 

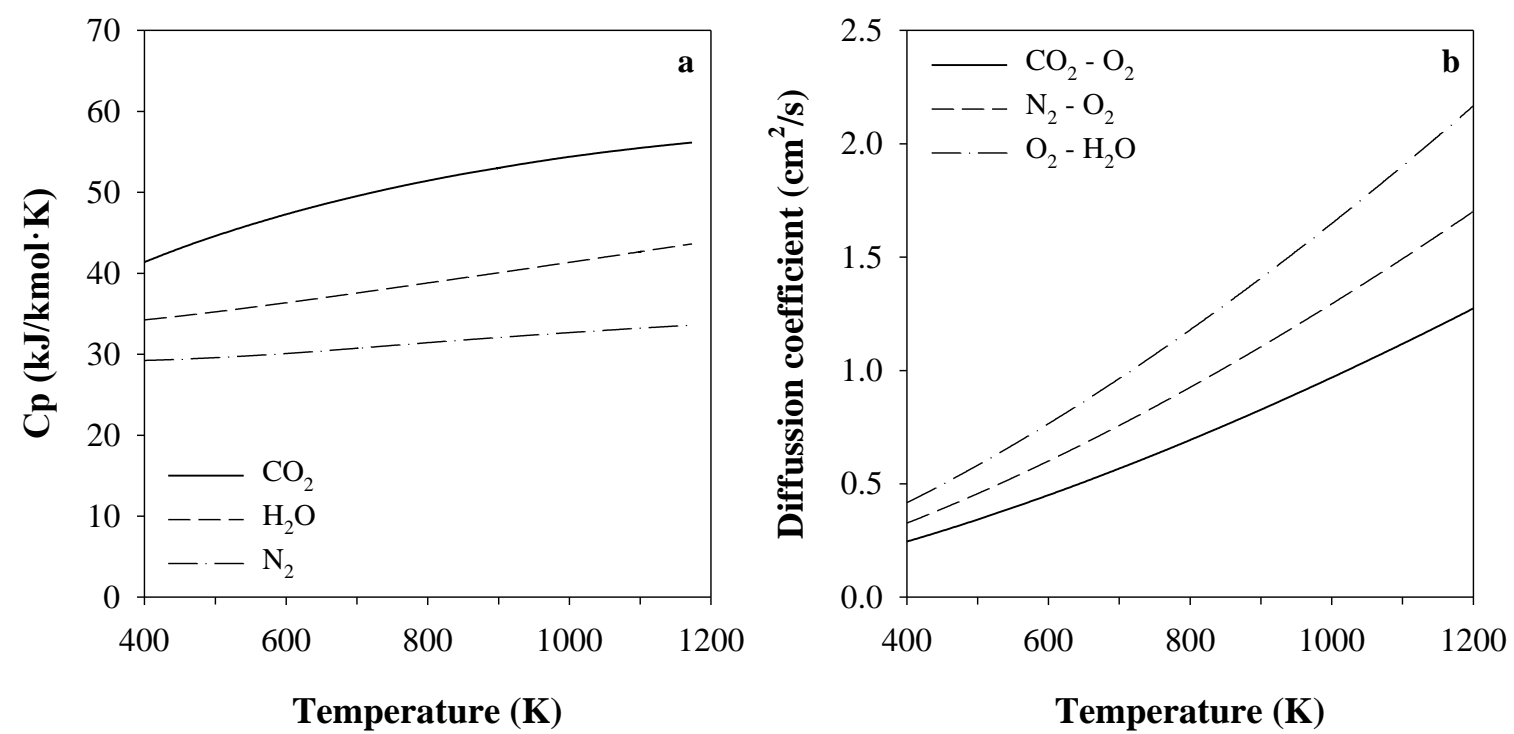

Figure 5. Properties of the gases used in this work. a) Specific heat; b) Diffusion coefficient. 


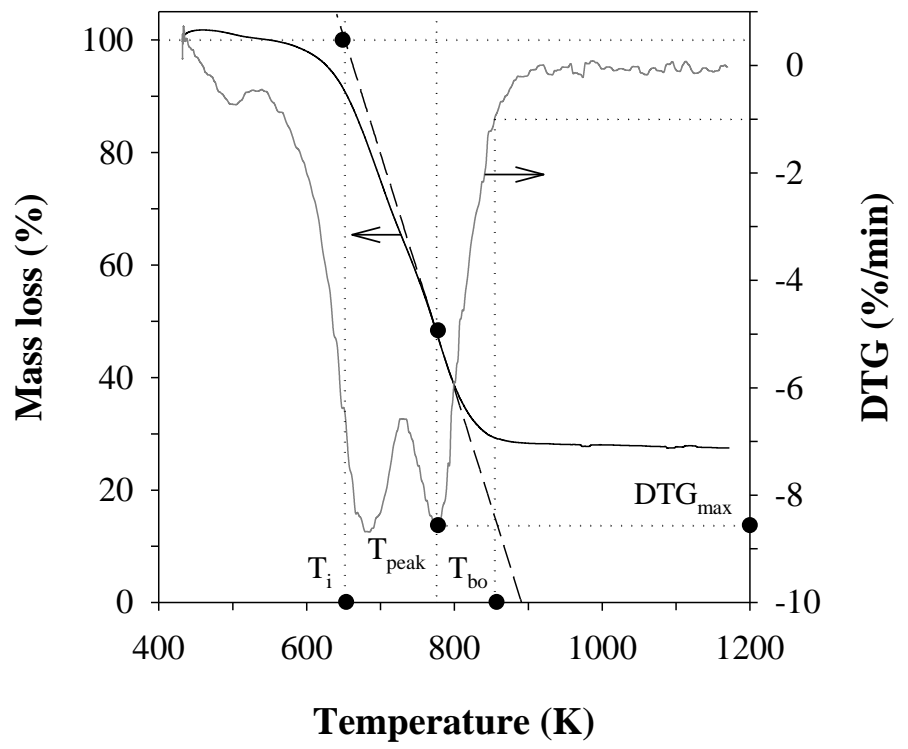

Figure 6. Calculation of the characteristic temperatures and maximum combustion rate. Coal B. 20 vol. $\% \mathrm{O}_{2}+$ 70 vol. $\% \mathrm{H}_{2} \mathrm{O}+10$ vol. $\% \mathrm{CO}_{2}$. 


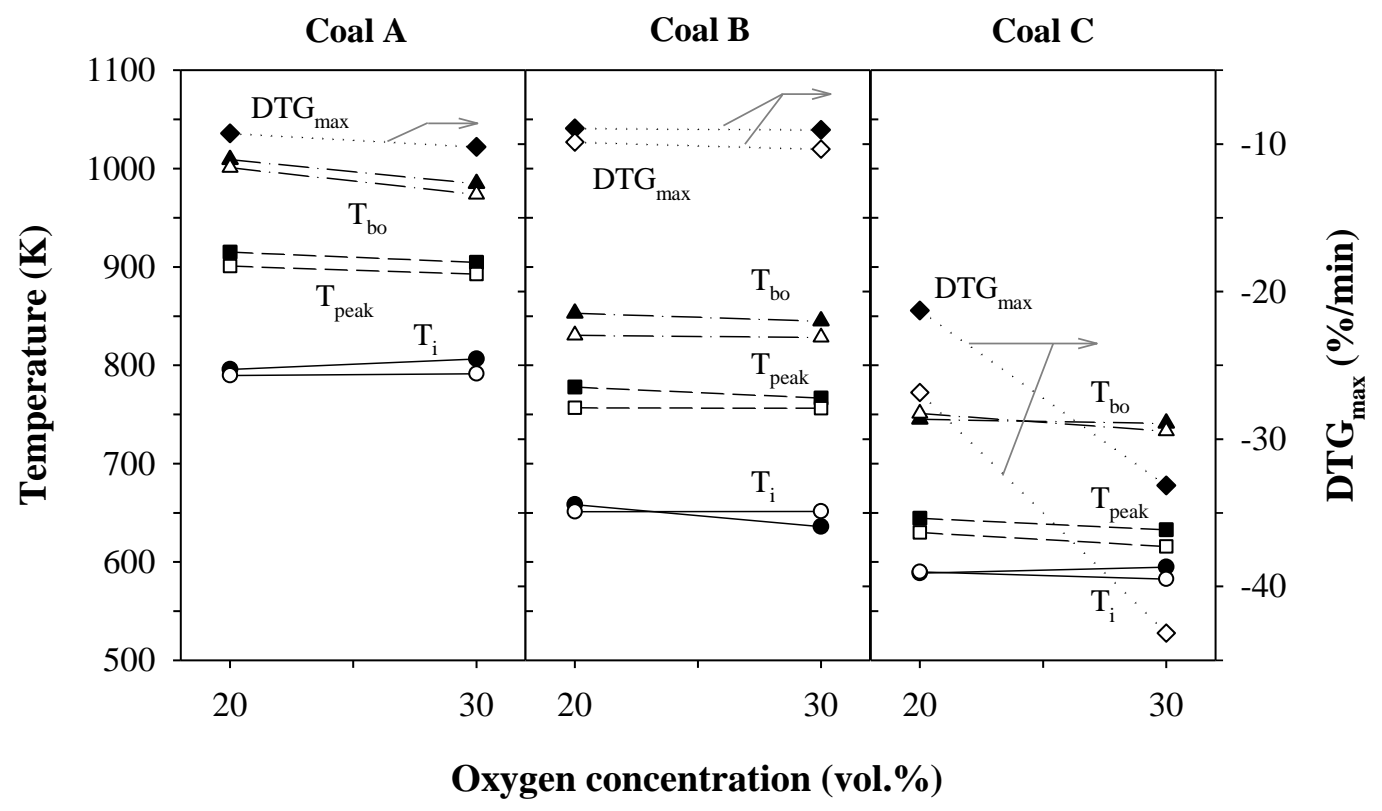

Figure 7. Combustion characteristic temperatures and maximum combustion rate under different oxygen concentrations. Filled symbols: $\mathrm{CO}_{2} ;$ Empty symbols: $\mathrm{N}_{2}$. 


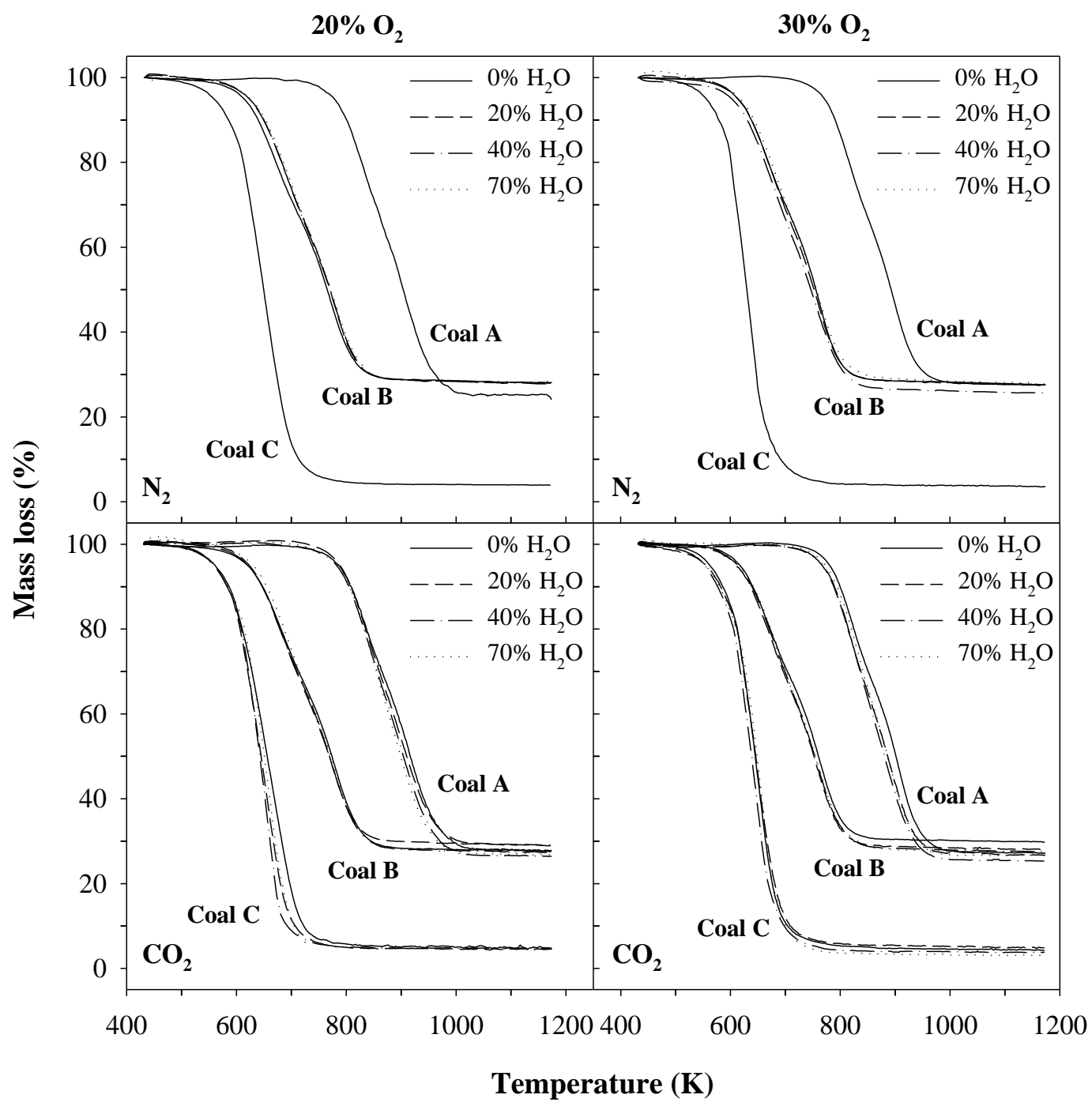

Figure 8. TG curves of combustion experiments with coals A, B and C under different reaction atmospheres with variable steam concentrations. 


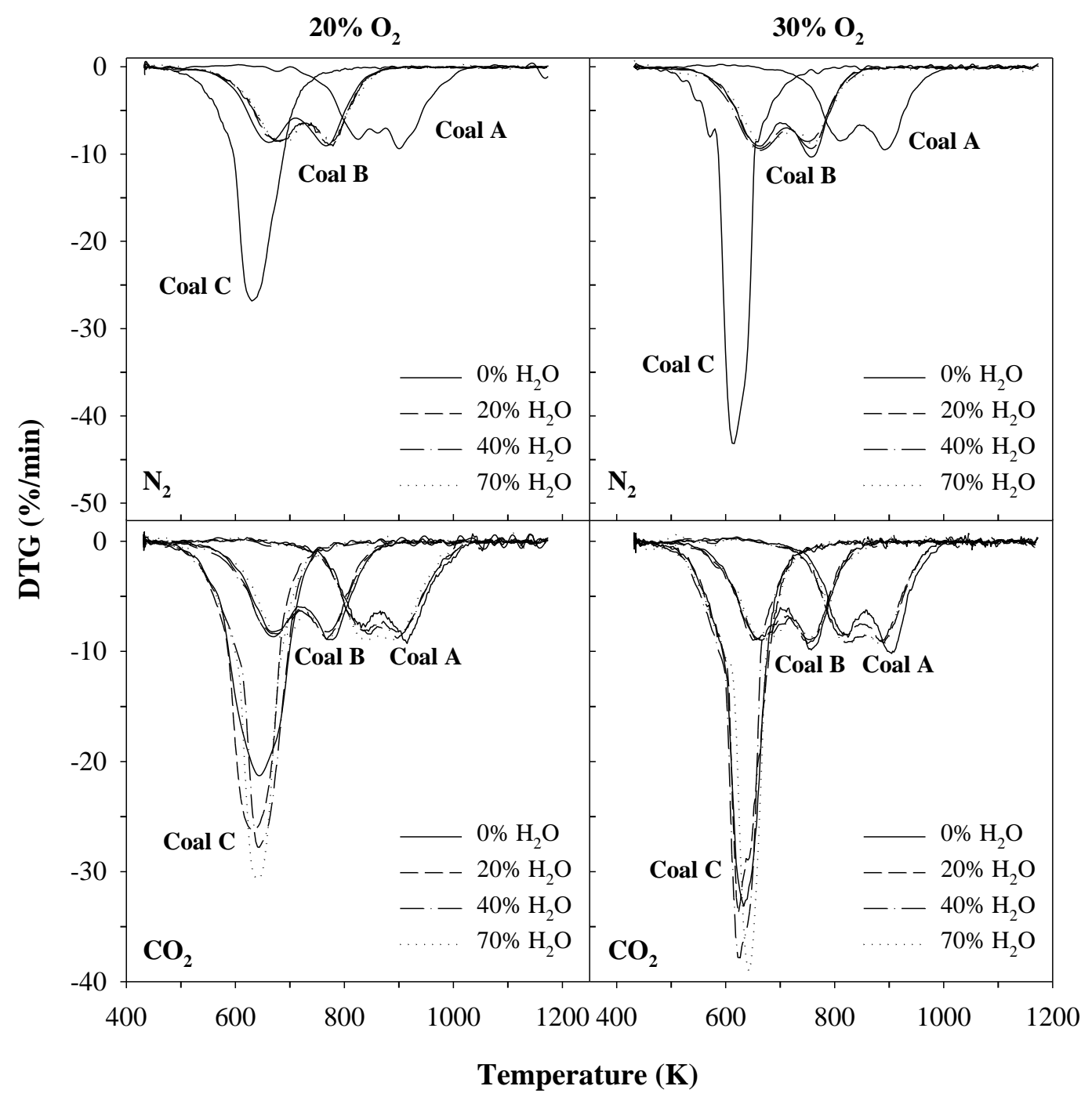

Figure 9. DTG curves of combustion experiments with coals A, B and C under different reaction atmospheres with variable steam concentrations. 


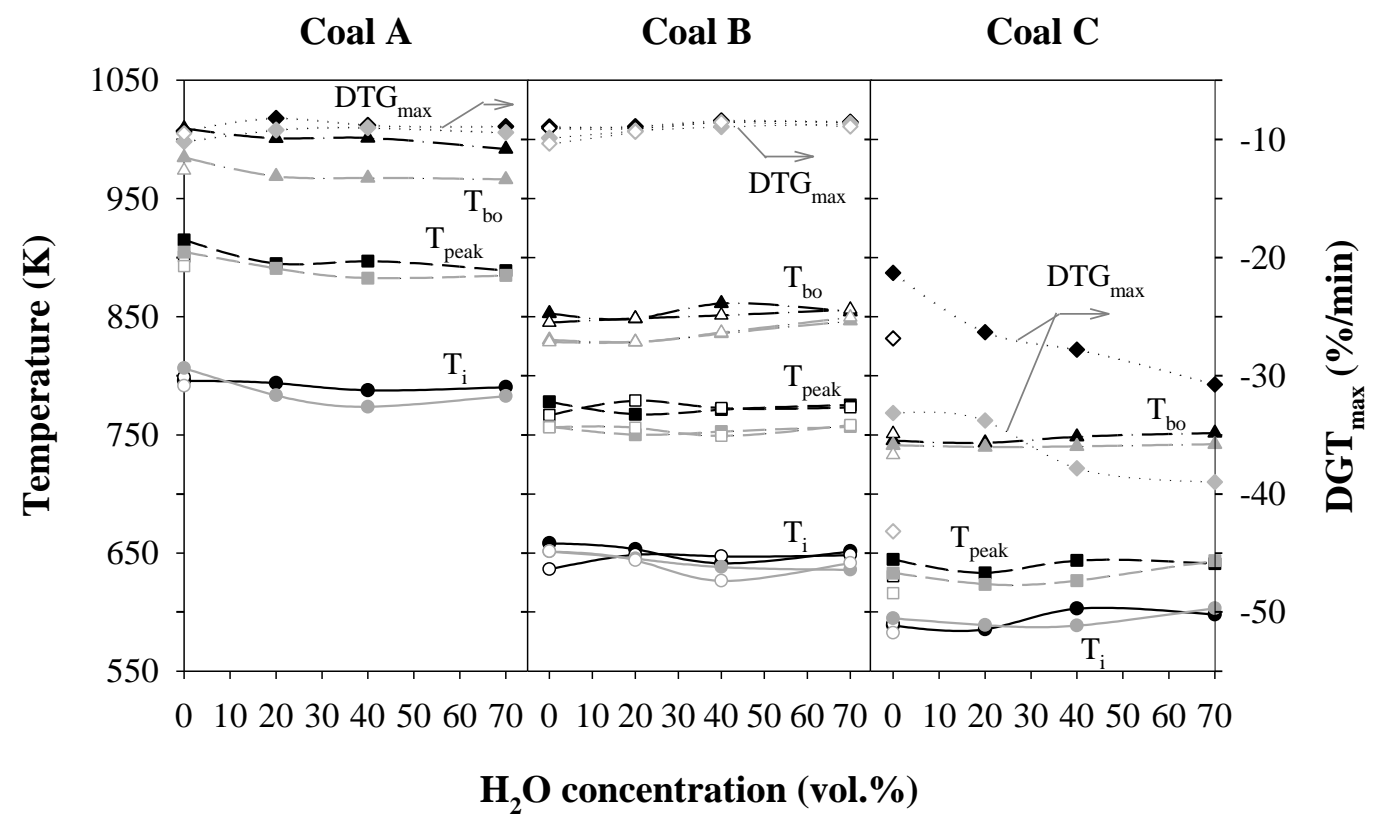

Figure 10. Combustion characteristic temperatures and maximum combustion rate under different steam concentrations. Black symbols: $20 \% \mathrm{O}_{2}$; Grey symbols: $30 \% \mathrm{O}_{2}$; Filled symbols: $\mathrm{CO}_{2}$; Empty symbols: $\mathrm{N}_{2}$. 


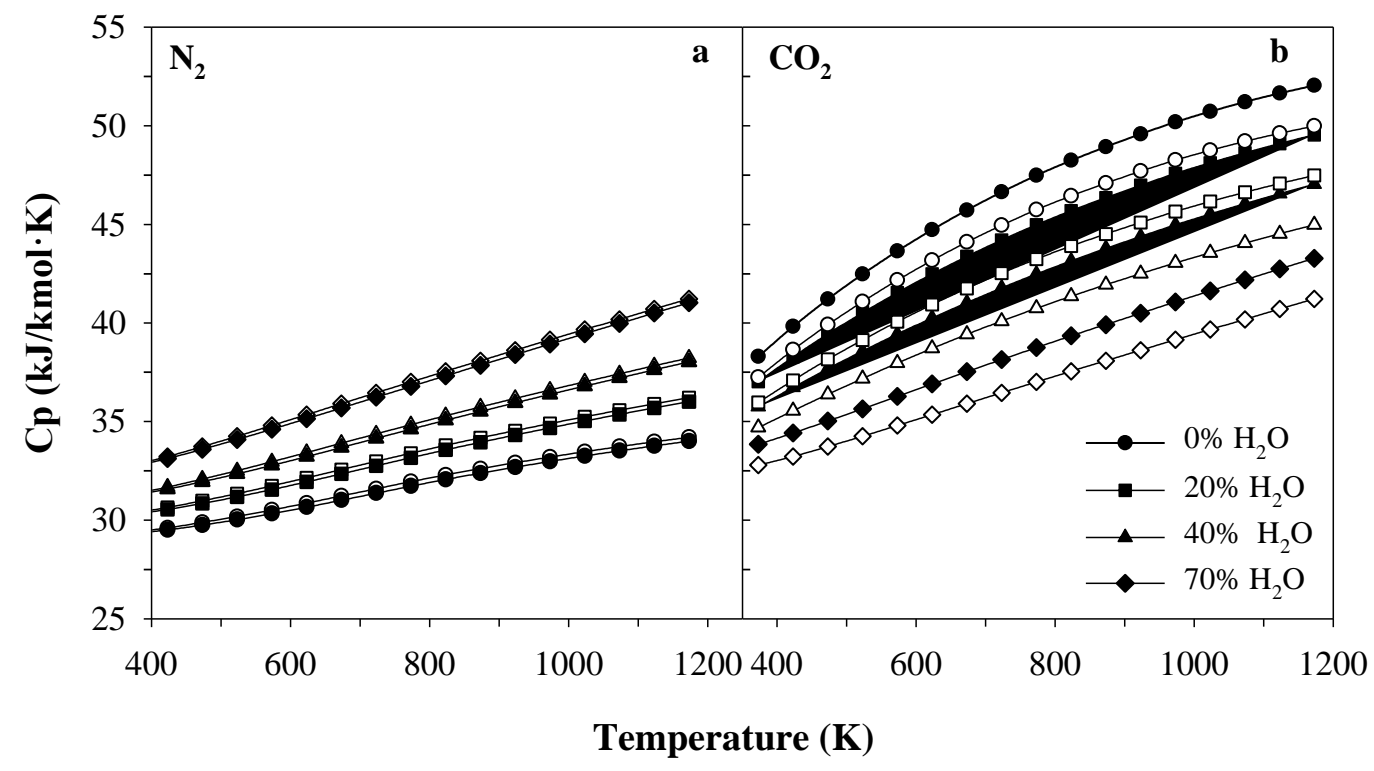

Figure 11. Heat capacity of different gaseous mixtures under variable $\mathrm{H}_{2} \mathrm{O}$ and $\mathrm{O}_{2}$ concentrations. . $\longrightarrow 0$ vol.\% $\mathrm{H}_{2} \mathrm{O} ; \longrightarrow 20 \mathrm{vol} . \% \mathrm{H}_{2} \mathrm{O} ; \longrightarrow 40 \mathrm{vol} . \% \mathrm{H}_{2} \mathrm{O} ; \longrightarrow 70$ vol. $\% \mathrm{H}_{2} \mathrm{O}$; filled symbols: 20 vol. $\% \mathrm{O}_{2}$ and empty symbols: 30 vol. $\% \mathrm{O}_{2}$. 


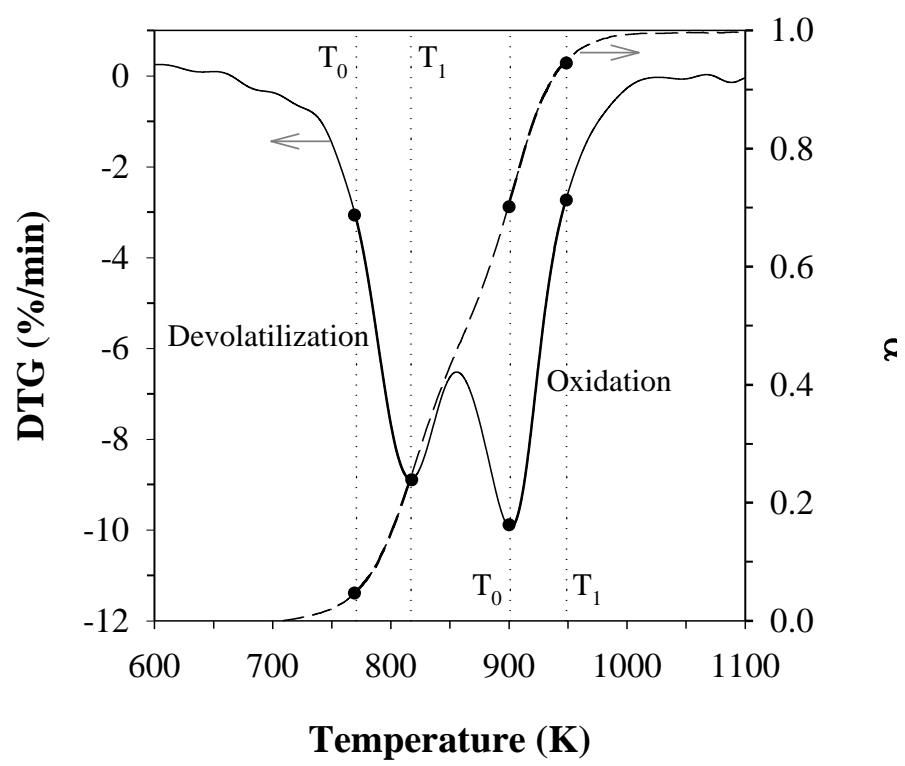

Figure 12. Data zones for the kinetics calculation of devolatilization and oxidation. Coal A. 30 vol. $\% \mathrm{O}_{2}+70$ vol. $\% \mathrm{CO}_{2}$. 

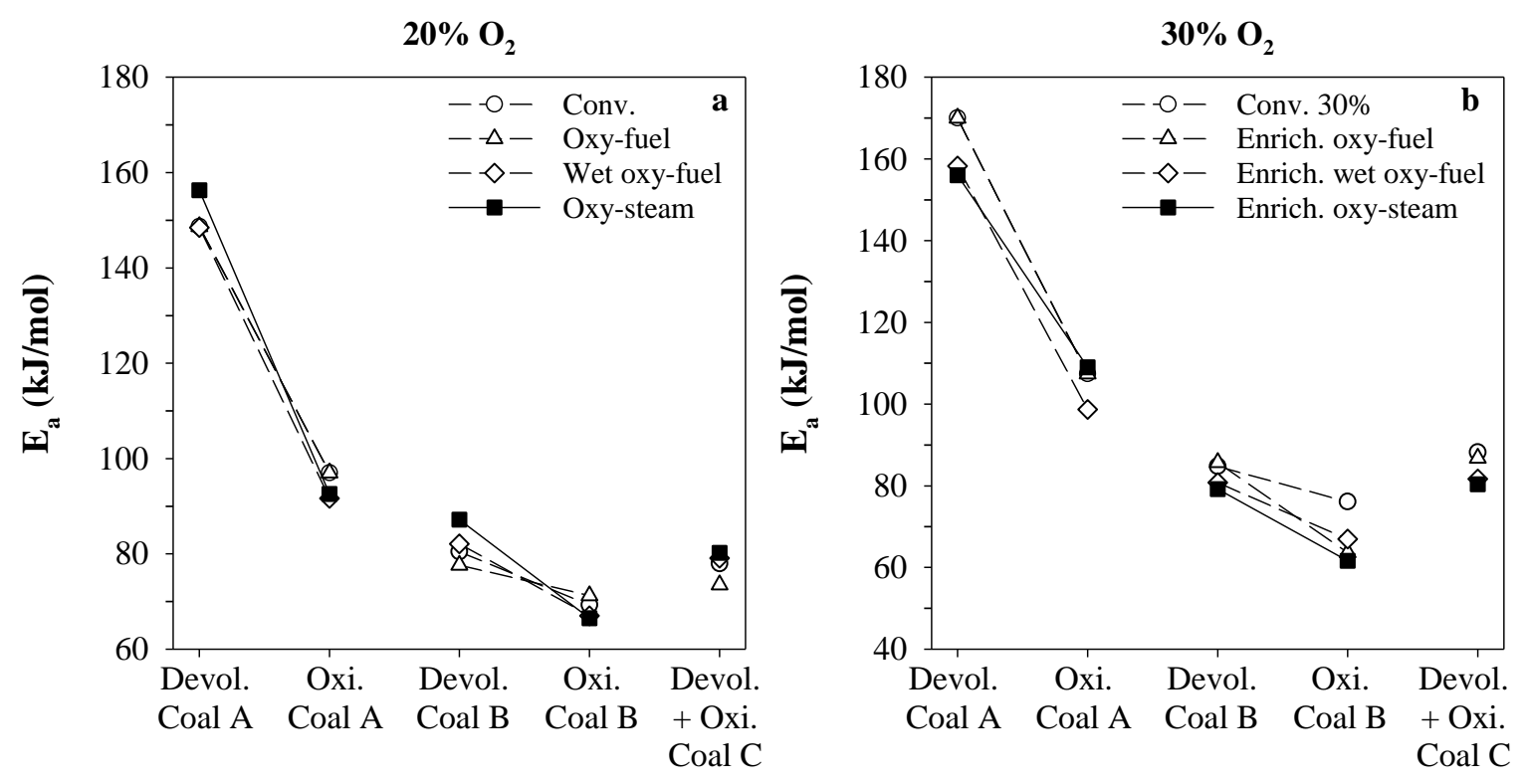

Figure 13. Activation energy, $E_{a}$, for different combustion conditions using coals A, B and C under a) 20 vol\% $\mathrm{O}_{2}$ and b) 30 vol. $\% \mathrm{O}_{2}$. 


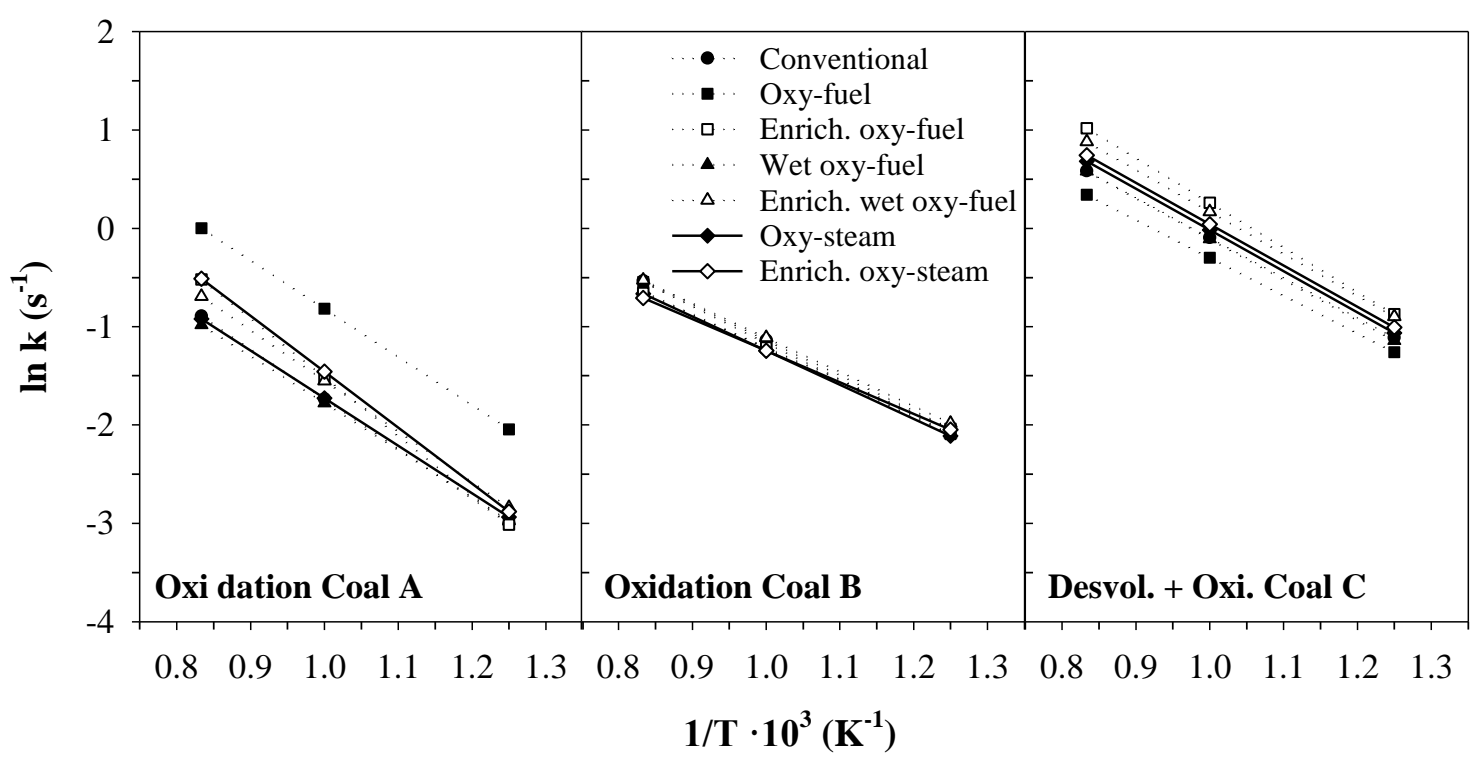

Figure 14. ln K of oxidation reaction in the range 800 to $1200 \mathrm{~K}$ for different combustion conditions with coals $\mathrm{A}, \mathrm{B}$ and $\mathrm{C}$. 